\title{
Benchmarking the vertically integrated ice-sheet model IMAU-ICE (version 2.0)
}

Constantijn J. Berends ${ }^{1}$, Heiko Goelzer ${ }^{2}$, Thomas J. Reerink ${ }^{3}$, Lennert B. Stap ${ }^{1}$, Roderik S. W. van de $\mathrm{Wal}^{1,4}$

$5 \quad{ }^{1}$ Institute for Marine and Atmospheric research Utrecht, Utrecht University, Utrecht, The Netherlands

${ }^{2}$ NORCE Norwegian Research Centre, Bjerknes Centre for Climate Research, Bergen, Norway

${ }^{3}$ Royal Netherlands Meteorological Institute KNMI, De Bilt, The Netherlands

${ }^{4}$ Faculty of Geosciences, Department of Physical Geography, Utrecht University, Utrecht, The Netherlands

Correspondence to: Constantijn J. Berends (c.j.berends@uu.nl)

10 Abstract. Ice-dynamical processes constitute a large uncertainty in future projections of sea-level rise caused by anthropogenic climate change. Improving our understanding of these processes requires ice-sheet models that perform well at simulating both past and future ice-sheet evolution. Here, we present version 2.0 of the ice-sheet model IMAU-ICE, which uses the depthintegrated viscosity approximation (DIVA) to solve the stress balance. We evaluate its performance in a range of benchmark experiments, including simple analytical solutions, as well as both schematic and realistic model intercomparison exercises.

15 IMAU-ICE has adopted recent developments in the numerical treatment of englacial stress and sub-shelf melt near the grounding-line, which result in good performance in experiments concerning grounding-line migration (MISMIP) and buttressing (ABUMIP). This makes it a model that is robust, versatile, and user-friendly, and which will provide a firm basis for (palaeo-)glaciological research in the coming years.

\section{Introduction}

20 Large-scale ice-sheet retreat is one of the most troubling long-term consequences of anthropogenic climate change (Oppenheimer et al., 2019; Fox-Kemper et al., 2021). Large uncertainties exist in projections of future ice-sheet retreat in strong warming scenarios, caused to a large extent by uncertainties in the dynamical response of the Greenland and Antarctic ice sheets (e.g. van de Wal et al., 2019). Since part of this response happens on centennial to millennial timescales, observational evidence alone cannot sufficiently reduce these uncertainties. Instead, models of large-scale ice-sheet dynamics should also be based on evidence of past changes in ice-sheet geometry.

Palaeoglaciological applications put different demands and constraints on ice-sheet models than future projections. Whereas future projections typically run for a few hundred years into the future at most, palaeo-simulations can cover periods of hundreds of thousands of years, requiring a high computational efficiency. Many physical processes that can be neglected on

30 the relative short timescales of typical future projections, such as glacial-isostatic adjustment (GIA), feedbacks of ice-sheet 
geometry on the regional climate, and changes in orbital configuration, need to be accounted for when the goal is to investigate multimillennial ice-sheet evolution. This means it is important that palaeo-ice-sheet models are robust and flexible enough to allow for such processes to be included, excluded, or altered without too much effort by the user.

5 In the early 2000's, the Institute for Marine and Atmospheric Research Utrecht (IMAU) developed ANICE, an ice-sheet-shelf model using hybrid SIA/SSA ice dynamics and a 3D thermodynamical module (Bintanja and van de Wal, 2008). Over the years this model has been continuously developed; a set-up was created where four copies of the model were coupled together to simulate the four large Pleistocene ice-sheets (North America, Eurasia, Greenland, and Antarctica) simultaneously (ANICE4; de Boer et al., 2013). Later, this four-region set-up was coupled to the global sea-level equation solver SELEN 10 (ANICE4-SELEN; de Boer et al., 2014). An inverse method of forcing the model using benthic $\delta^{18} \mathrm{O}$ records was developed (de Boer et al., 2014), and a matrix method to force the model with GCM time slices was created (ANICE2.1; Berends et al., 2018 ) and later combined with the inverse forcing method to create a strategy to reconstruct past changes in $\mathrm{CO}_{2}$ (Berends et al., 2019). Around 2016, development of IMAU-ICE started: the spiritual successor of ANICE, still solving the same physical equations, but with a thoroughly overhauled code structure, aimed at a wider range of possible applications, including future

15 projections. The first result of this effort, IMAU-ICE v1.0, has been used in several research projects involving future projections (e.g. Goelzer et al., 2018, 2020a, 2020b; Seroussi et al., 2019, 2020; Levermann et al., 2020; Sun et al., 2020; Edwards et al., 2021; Payne et al., 2021), as well as palaeo-applications (Bradley et al., 2018).

One particular aspect of the model that did not change much between subsequent members of the ANICE/IMAU-ICE model 20 family is the ice-dynamical solver, which was based on the hybrid SIA/SSA developed for PISM (Bueler and Brown, 2009). Since this heuristic method of combining the velocities from the two different approximations was first presented, its relative simplicity, computational efficiency, and good performance at simulating large-scale ice-sheet dynamics have led many research groups to adopt it as the basis for their own ice-sheet models (e.g. SICOPOLIS; Greve et al., 2011; f.ETISh; Pattyn, 2017; GRISLI; Quiquet et al., 2018; Yelmo; Robinson et al., 2020; UFEMISM; Berends et al., 2021b). However, the hybrid

25 SIA/SSA method has been shown to yield unsatisfactory results for geometries where features of the underlying bedrock are no longer very large or very small compared to the ice thickness (Pattyn et al., 2008). These shortcomings are considered to be small when the model resolution is large (as is the case for most palaeo-ice-sheet models, which typically use resolutions ranging between $10-100 \mathrm{~km}$ ). However, using such a coarse resolution can result in the smoothing out of topographical features such as fjords and pinning points, which can lead to erroneous ice velocities even when purely numerical errors are still small (Cuzzone et al., 2019).

Only two years after the popular hybrid SIA/SSA approach was published by Bueler and Brown (2009), another vertically integrated approximation to the stress balance was derived by Goldberg (2011). The "depth-integrated viscosity approximation" (DIVA) approximates the first-order momentum balance, and was derived using variational methods. It 
captures the longitudinal shear stresses included in the SSA, the vertical shear stress included in the SIA, plus the stress due to longitudinal stretching caused by vertical shearing (present in neither the SIA nor the SSA). It can therefore be viewed as a more mathematically consistent derivation of the dynamical equations which are heuristically approximated by the hybrid SIA/SSA. Goldberg (2011) applied the DIVA to the experiments from the ISMIP-HOM intercomparison (Pattyn et al., 2008),

5 and showed that it produces results that agree with those from higher-order and full-Stokes models down to spatial scales as small as $10 \mathrm{~km}$. Goldberg (2011) also showed that the DIVA was nearly as simple to implement as the hybrid SIA/SSA approximation, and Robinson et al. (2021) showed that it was significantly faster than other vertically integrated schemes at high $(<5 \mathrm{~km})$ resolutions, due to the superior numerical stability and consequently larger time steps. Despite these advantages, the DIVA is, to our knowledge, currently only used in CISM (Lipscomb et al., 2019) and Yelmo (Robinson et al., 2021).

In this paper we present a detailed description of IMAU-ICE v2.0 and the benchmarking experiments performed. Sect. 2 provides a general description of IMAU-ICE, and describes the implementation of the DIVA in IMAU-ICE. In Sect. 3 we compare model results to several analytical solutions, demonstrating that the numerical solvers work as intended. In Sect. 4 we present our results of the EISMINT-I (Huybrechts et al., 1996), ISMIP-HOM (Pattyn et al., 2008), MISMIP (Pattyn et al.,

15 2012), and ABUMIP (Sun et al., 2020) intercomparison exercises. In Sect. 5 we conclude with a discussion of the relative merits of IMAU-ICE with respect to other widely-used ice-sheet models, and of the various improvements that we have planned for IMAU-ICE in the foreseeable future.

\section{Model description}

\subsection{General model description}

20 IMAU-ICE v2.0 by default solves the DIVA approximation to the stress balance to find the englacial velocity field; other stress-balance approximations (SIA, SSA, hybrid SIA/SSA) are available for specific experiments and testing. The mass conservation equation is integrated through time using an explicit solver; a semi-implicit solver is available, offering improved numerical stability at an increased computational expense. The model has a dynamic time-step, which is calculated using a predictor/corrector method to provide an estimate of the truncation error in the ice thickness (Cheng et al., 2016). The implementation of this method is adopted from Yelmo (Robinson et al., 2020). The model is thermomechanically coupled; the vertical coordinate is discretised using an irregularly-spaced scaled coordinate, and the heat equation is solved on the resulting 3-D grid. The version of the heat equation that is solved by the model includes horizontal and vertical advection, vertical (but not horizontal) diffusion, strain heating from vertical shearing, and a spatially variable geothermal heat flux (by default obtained from Shapiro and Ritzwoller, 2004) at the base of grounded ice. A derivation of this equation and its discretisation is

30 provided by Berends et al. (2021b). The englacial temperature is used to determine the flow factor for Glen's flow law using an Arrhenius relation, following Huybrechts (1992). 
IMAU-ICE v2.0 is suitable for both future projections of Greenland and Antarctica, as well as for simulations of glacial cycles. For the latter purpose, the model can simultaneously simulate the evolution of ice-sheets in four model regions: North America, Eurasia, Greenland, and Antarctica, shown in Fig. 1. To prevent double-counting, no ice growth is permitted on the Greenlandic parts of the North American and Eurasian model regions, or on the Icelandic parts of the Greenland region.
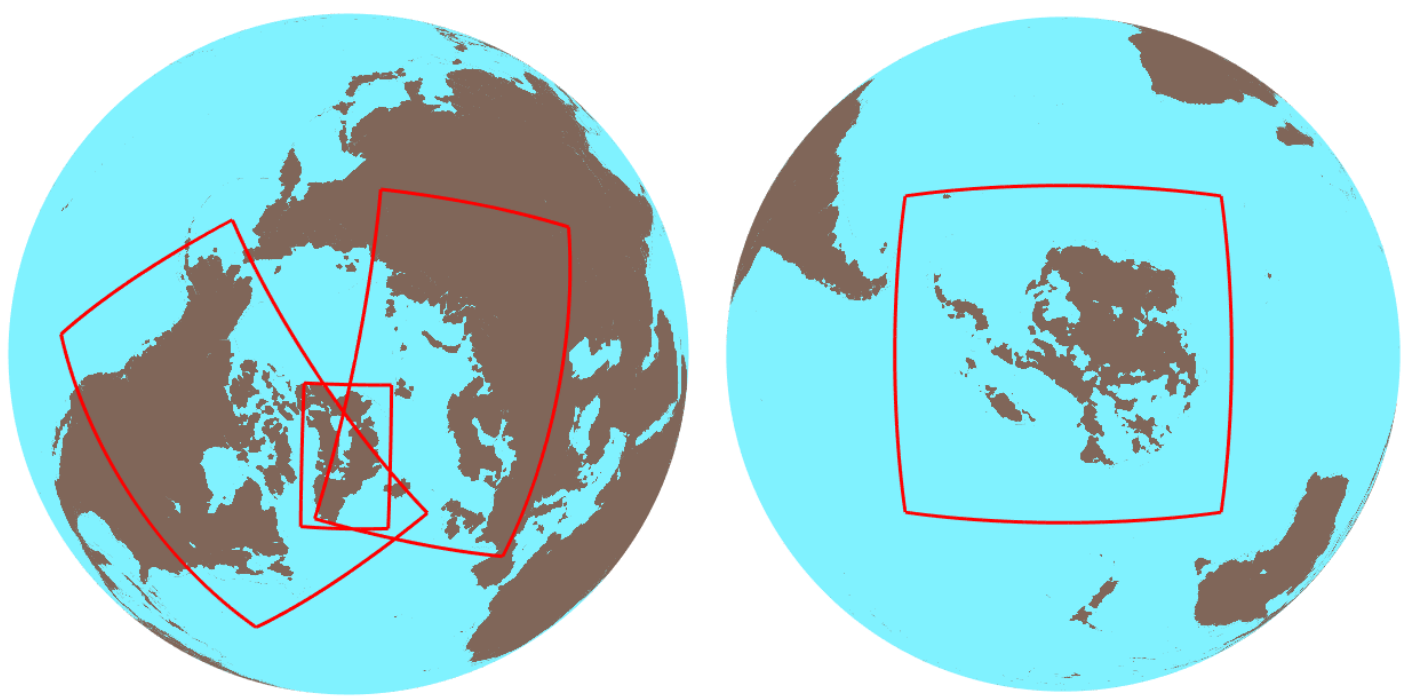

Figure 1: The four model regions of IMAU-ICE.

\subsection{Ice dynamics: the depth-integrated viscosity approximation}

As given by Goldberg (2011), the equations for the DIVA stress balance read:

$$
\begin{aligned}
& \frac{\partial}{\partial x}\left[2 \bar{\eta} H\left(2 \bar{u}_{x}+\bar{v}_{y}\right)\right]+\frac{\partial}{\partial y}\left[\bar{\eta} H\left(\bar{u}_{y}+\bar{v}_{x}\right)\right]-\beta_{e f f} \bar{u}=-\tau_{d, x} . \\
& \frac{\partial}{\partial y}\left[2 \bar{\eta} H\left(2 \bar{v}_{y}+\bar{u}_{x}\right)\right]+\frac{\partial}{\partial x}\left[\bar{\eta} H\left(\bar{v}_{x}+\bar{u}_{y}\right)\right]-\beta_{e f f} \bar{v}=-\tau_{d, y} .
\end{aligned}
$$

Here, the two square-bracket terms on the left-hand side represent the "membrane stresses" from longitudinal stretching and

lateral shearing, while the term $\beta_{\text {eff }} u$ represents both the frictional shear stress at the base, and the viscous stress from vertical shearing in the ice, with $\mathrm{H}$ being the ice thickness. These stresses are balanced by the gravitational driving stress on the righthand side. The vertically averaged effective viscosity $\bar{\eta}$ is determined as a function of the temperature-dependent flow factor $A$ and the effective strain rate $\dot{\varepsilon}_{e}$ :

$$
\begin{gathered}
\bar{\eta}=\frac{1}{H} \int_{b}^{s} \eta(z) d z=\frac{1}{H} \int_{b}^{s} \frac{1}{2} A^{\frac{-1}{n}} \dot{\varepsilon}_{e}^{\frac{1-n}{n}} d z \\
\dot{\varepsilon}_{e}^{2}=\bar{u}_{x}^{2}+\bar{v}_{y}^{2}+\bar{u}_{x} \bar{v}_{y}+\frac{1}{4}\left[\bar{u}_{y}+\bar{v}_{x}\right]^{2}+\frac{1}{4} \bar{u}_{z}+\frac{1}{4} \bar{v}_{z}
\end{gathered}
$$

The term $\beta_{e f f}$ is related to the basal friction term $\beta$, but includes an additional term that accounts for the vertical shear stress: 


$$
\begin{gathered}
\beta_{\text {eff }}=\frac{\beta}{1+\beta F_{2}} \\
F_{n}=\int_{b}^{s} \frac{1}{\eta(z)}\left(\frac{s-z}{H}\right)^{n} d z
\end{gathered}
$$

A comprehensive derivation of these equations is provided by Lipscomb et al. (2019). The way the DIVA is solved numerically in IMAU-ICE v2.0 is mostly adopted from Yelmo (Robinson et al., 2021), and is very similar to typical SSA solvers, using an "outer loop" where the effective viscosity, the effective basal friction, and the velocities are iteratively updated until the solution converges.

Rather than applying stress boundary conditions at the ice margin, IMAU-ICE follows the "infinite slab" approach used by e.g. Ritz et al. (2001) and Pattyn (2017), where ice-free pixels are still assigned a viscosity (as if there were a very thin layer of ice present), so that the velocity equations are solved over the entire model domain. At the domain boundary, a simple Neumann boundary condition is prescribed.

\section{$10 \quad$ 2.3 Sliding, grounding-line migration, and calving}

As in earlier model versions, IMAU-ICE v2.0 uses a regularised Coulomb-type sliding law similar to Pattyn (2017), where the till friction angle and basal yield stress are calculated following Martin et al. (2011). Here, the basal friction $\boldsymbol{\tau}_{b}$ is related to the basal velocity $\boldsymbol{u}_{b}$ and the basal yield stress $\boldsymbol{\tau}_{c}$ :

$$
\boldsymbol{\tau}_{b}=\tau_{c} \frac{\left|\boldsymbol{u}_{b}\right|^{q-1} \boldsymbol{u}_{b}}{u_{0}^{q}} .
$$

This results in the following expression for the sliding term $\beta$ :

$$
\beta=\frac{\tau_{c}\left|\boldsymbol{u}_{b}\right|^{q-1}}{u_{0}^{q}} .
$$

15 The basal yield stress $\tau_{c}$ is related to the pore water pressure $p_{w}$ and the till friction angle $\varphi$ :

$$
\tau_{c}=\tan \varphi\left(\rho_{i} g H-p_{w}\right)
$$

Here, the term between brackets is the effective overburden pressure. The till friction angle and pore water pressure are parameterised respectively as functions of the bedrock elevation $b$ and the water depth $d_{w}=z_{S L}-b$ :

$$
\begin{gathered}
\varphi=w_{b} \varphi_{\text {max }}+\left(1-w_{b}\right) \varphi_{\text {min }} \\
w_{b}=\frac{b-b_{\min }}{b_{\max }-b_{\min }} \\
p_{w}=0.96 \rho_{i} g H \lambda_{w} \\
\lambda_{w}=\frac{d_{w}}{d_{\text {sat }}}
\end{gathered}
$$


The scaling factors $w_{b}$ and $\lambda_{w}$ are limited between 0 and 1 . The default values of the different constants (all of which can be changed at run-time in IMAU-ICE through the configuration file) are listed in Table 1. These parameters are uniform over the model domain; the spatial variability in the friction coefficient is introduced by the bedrock elevation.

Table 1: constants used in the till model and sliding law

\begin{tabular}{clll} 
Symbol & Description & Units & Value \\
\hline$u_{0}$ & Threshold velocity in regularised Coulomb sliding law & $\mathrm{m} \mathrm{yr}^{-1}$ & 100 \\
$q$ & Exponent in regularised Coulomb friction law & & 0.3 \\
$\varphi_{\min }$ & Minimum till friction angle (when $\left.b=b_{\min }\right)$ & degrees & 5 \\
$\varphi_{\max }$ & Maximum till friction angle $\left(\right.$ when $\left.b=b_{\max }\right)$ & degrees & 20 \\
$b_{\min }$ & Lower bedrock elevation threshold for till friction angle & $\mathrm{m}$ & -1000 \\
$b_{\text {max }}$ & Upper bedrock elevation threshold for till friction angle & $\mathrm{m}$ & 0 \\
$d_{\text {sat }}$ & Water depth where pore saturation occurs & $\mathrm{m}$ & 1000
\end{tabular}

In order to accurately reproduce grounding-line migration, IMAU-ICE follows the approach used in PISM (Feldmann et al., 2014) and in CISM (Leguy et al., 2021) by scaling the basal friction term $\beta_{\text {eff }}$ near the grounding line with the square of the sub-grid grounded fraction. The sub-grid grounded fraction is found by bilinearly interpolating the thickness above floatation, using the analytical solution derived by Leguy et al. (2021). As we will show in Sect. 4.3, this approach results in grounding-

10 line hysteresis smaller than the grid resolution in the MISMIP experiment. Preliminary experiments with the grounding-line flux condition that was used in IMAU-ICE v1.0 (following the approach of Pollard and DeConto, 2012, and Pattyn, 2017) showed that this approach yields similar results in the schematic MISMIP experiments, but made it more difficult to maintain numerical stability in realistic applications.

We note that our approach differs from that of PISM (Feldmann et al., 2014) and CISM (Lipscomb et al., 2019) in that we

15 scale $\beta_{\text {eff }}$ with the square of the grounded fraction, rather than with the grounded fraction itself. We found that this yields less ice-sheet asymmetry and grounding-line hysteresis in the MISMIP experiment. The discrepancy might be caused by the fact that PISM uses one-sided differencing to calculate the driving stresses in next-to-grounding-line grid cells (they define SSA velocities on the regular grid, in contrast to our staggered approach). In CISM, velocities are defined on the double-staggered Arakawa B-grid, possibly introducing some additional numerical diffusion when calculating the fluxes in the ice thickness 20 integration.

Calving is parameterised in IMAU-ICE v2.0 by a simple threshold-thickness calving law, with a default threshold thickness of $200 \mathrm{~m}$. 


\subsection{Glacial isostatic adjustment}

Two options for glacial isostatic adjustment (GIA) are included: a simple ELRA (Elastic Lithosphere, viscously Relaxed Asthenosphere) model with eustatic sea-level change, and the more elaborate sea-level equation solver SELEN (Spada and Stocchi, 2007), which includes the self-gravitating effects of both ice and ocean loading for all four ice sheets, coastline

5 migration, and rotational feedback. SELEN solves these equations globally using spherical harmonics. The coupling to SELEN was first set up by de Boer et al. (2014) for ANICE, and has been restructured for IMAU-ICE v2.0 to provide more flexibility and user-friendliness. The code of SELEN has also been parallelised, so that including SELEN in a 120-kyr glacial cycle simulation (with a coupling interval of $1 \mathrm{kyr}$ ) now adds only about 1 wall clock hour (24 core hours) when running the simulation at a spectral resolution of harmonic degree 64 on a 24-core system. At harmonic degree 128, this increases to 6 wall

10 clock hours (144 core hours).

\subsection{Climate and mass balance}

IMAU-ICE v2.0 by default uses the climate matrix method from Berends et al. (2018) to calculate the surface climate. In this approach, output from simulations of the pre-Industrial (PI) and Last Glacial Maximum (LGM) climate from the HadCM3 GCM (Singarayer and Valdes, 2010) is combined using spatially variable weights that depend on externally prescribed $\mathrm{CO}_{2}$

15 and internally modelled ice-sheet geometry. This method reproduces the general features of the ice-albedo feedback, the elevation-temperature feedback, and the orographic forcing of precipitation, resulting in a modelled climate that is mutually consistent with the modelled ice-sheet geometry. Previous work by Berends et al. (2018) shows that this method resulted in simulated ice-sheet geometries at the LGM that agreed significantly better with geomorphological evidence than those from more simplistic climate index forcing methods. The option to use a prescribed climate or SMB forcing is included, which is useful for future projections or schematic experiments.

The surface mass balance (SMB) is obtained from the calculated/prescribed climate using the insolation-temperature model IMAU-ITM (Berends et al., 2018). This model uses parameterisations to partition precipitation into snow and rain, calculate snow melt as a function of insolation and surface temperature, calculate refreezing, and calculate the albedo. IMAU-ITM participated in the recent GrSMBMIP intercomparison exercise (Fettweis et al., 2020), where it was shown to perform well at simulating the recent mass balance of Greenland, at a very low computational cost.

The basal mass balance is by default calculated using the (linear) temperature/depth-dependent sub-shelf melt parameterisation by Martin et al. (2011), combined with the glacial/interglacial parameterisation and the subtended-angle/distance-to-open-

30 ocean parameterisation by Pollard and DeConto (2009). The melt rates for protected (exposed) shelves during glacial (interglacial) periods were tuned by de Boer et al. (2013) to produce realistic present-day Antarctic shelves and grounding lines. The option to use a spatially uniform sub-shelf melt rate is included, which is useful for e.g. the ABUMIP experiments. 
Sub-shelf melt is applied only to grid cells floating at the centre, using the "floatation criterion melt parameterisation" (FCMP) scheme formulated by Leguy et al. (2021). The "no melt parameterisation" (NMP; melt only applied to fully floating grid cells) and "partial melt parameterisation" (PMP; melt scaled with the sub-grid floating fraction) are available in the model. We will briefly discuss the effect of this choice of sub-grid scheme in the context of the ABUMIP experiment in Sect. 4.4.

\section{Analytical solutions}

In this section we present results from a number of schematic experiments that have analytical solutions. These concern only the SIA and SSA; no analytical solution to the DIVA has yet been derived. However, since the numerical solvers for the SSA and the DIVA are nearly identical, proving that the SSA is solved correctly provides confidence that our DIVA solver is also functioning properly. This will be confirmed in Sect. 4, where we perform the ISMIP-HOM benchmark experiments.

\section{$10 \quad 3.1$ Shallow ice approximation}

Halfar (1981) derived an analytical solution to the SIA for the case of a radially symmetrical, isothermal ice sheet on a flat bed with zero mass balance. Since the ice sheet evolves only through ice dynamics, this is a useful experiment for verifying icesheet model numerics. Bueler et al. (2005) extended this solution to include a parameterised mass balance term. Comprehensive descriptions of these experiment and their analytical solutions are provided by Berends et al. (2021b). The ice-margin errors

15 as function of model resolution for both experiments as simulated by IMAU-ICE v2.0 are shown in Fig. 2, with log-linear curves fitted to both sets of results. Both experiments show a convergence of ice-margin position error with model resolution of approximately the first order, indicating that the numerical schemes used to solve the SIA and integrate the ice thickness equation are valid.

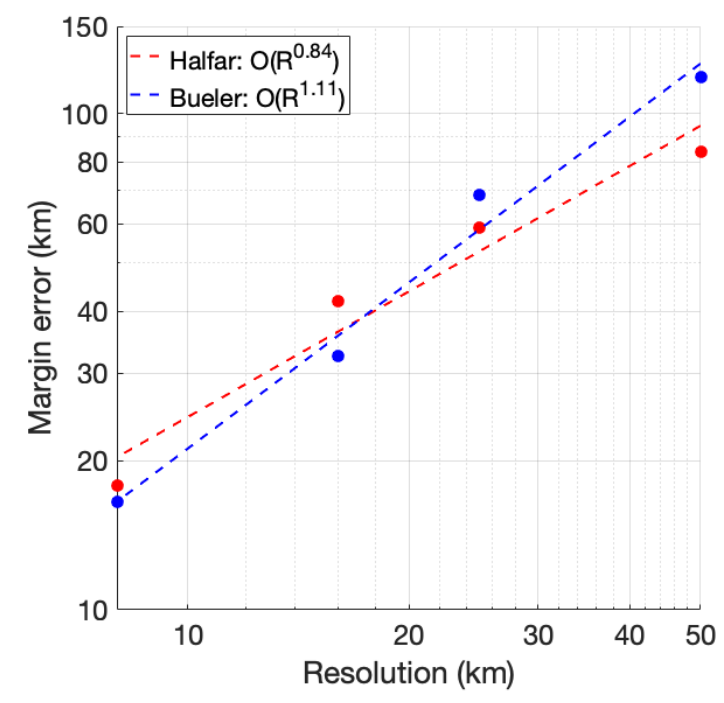


Figure 2: The error in the simulated ice-margin position as a function of horizontal model resolution for the Halfar and Bueler dome experiments.

\subsection{Shallow shelf approximation}

Schoof (2006) derived an analytical solution to the SSA for the case of an ice slab on a sloping bed, with a narrow band of lower friction running down the slope, resulting in the formation of an ice stream; a complete description of the experiment is provided by Bueler and Brown (2009). We performed this experiment at resolutions ranging from $5 \mathrm{~km}$ to $250 \mathrm{~m}$. The results are shown in Fig. 3; as can be seen, the simulated velocities match the analytical solution at all resolutions.

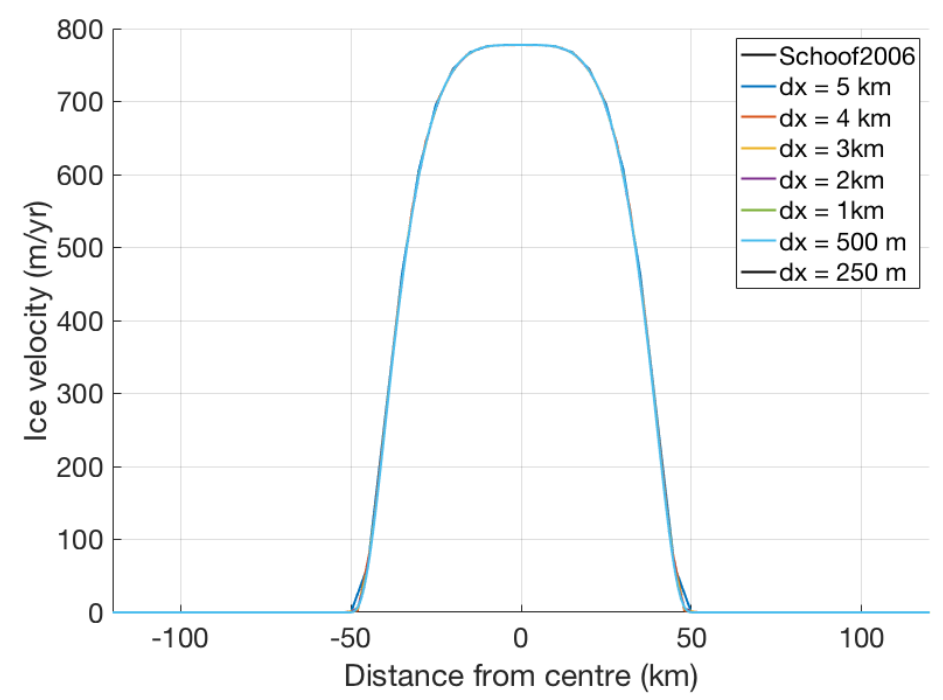

Figure 3: Cross-slope transects of the downslope velocity in the Schoof (2006) ice-stream experiment at different resolutions.

\section{Model intercomparison}

In this section we perform experiments from the EISMINT-I (Huybrechts et al., 1996), ISMIP-HOM (Pattyn et al., 2008), MISMIP (Pattyn et al., 2012), and ABUMIP (Sun et al., 2020) model intercomparison projects, to demonstrate that IMAUICE performs adequately when compared to other ice-sheet models. The DIVA is used in all of these experiments, except for EISMINT-I, which considers only the SIA.

\section{$15 \quad 4.1$ EISMINT-I}

The first EISMINT intercomparison exercise (Huybrechts et al., 1996) consists of six schematic experiments (see Table 2) similar to the Halfar dome, but with a parameterised mass balance that is independent of ice geometry. In experiments a and $\mathrm{d}$, the mass balance is positive in the centre of the domain and decreases away from the ice divide, yielding a circular steadystate ice sheet. In experiments b and e, a $20 \mathrm{kyr}$ sinusoid term is added to the mass balance to represent glacial cycles; in 
experiments $\mathrm{c}$ and $\mathrm{f}$, the period is increased to $40 \mathrm{kyr}$. Experiments $\mathrm{a}, \mathrm{b}$, and $\mathrm{c}$ have a moving margin, achieved by prescribing the mass balance such that even at glacial maxima, the ice margin does not reach the edge of the domain. In experiments d, e, and $\mathrm{f}$, the mass balance is increased such that even at glacial minima, the ice margin should lie outside the domain; a zero ice thickness boundary condition is prescribed at the domain boundary instead, leading to a fixed margin. These experiments include uncoupled thermodynamics; the englacial temperature is calculated, but does not affect the ice flow factor (which is spatially and temporally constant). All of these experiments were performed at the original EISMINT-I resolution of $50 \mathrm{~km}$. Fig. 4 shows the thickness at the ice divide for the four "glacial cycle" experiments (b, c, e, and f). Fig. 5 shows the simulated ice temperature at the base of the ice divide relative to the pressure melting point for the same set of experiments. For all four experiments, we find glacial-interglacial differences for both ice thickness and basal temperature that lie within, or very slightly outside of, the range of values reported by Huybrechts et al. (1996).

Table 2: The six different EISMINT experiments.

\begin{tabular}{lll} 
Experiment & Margin & Mass Balance \\
\hline a & moving & steady-state \\
b & moving & $20 \mathrm{kyr}$ \\
c & moving & $40 \mathrm{kyr}$ \\
d & fixed & steady-state \\
e & fixed & $20 \mathrm{kyr}$ \\
f & fixed & $40 \mathrm{kyr}$
\end{tabular}
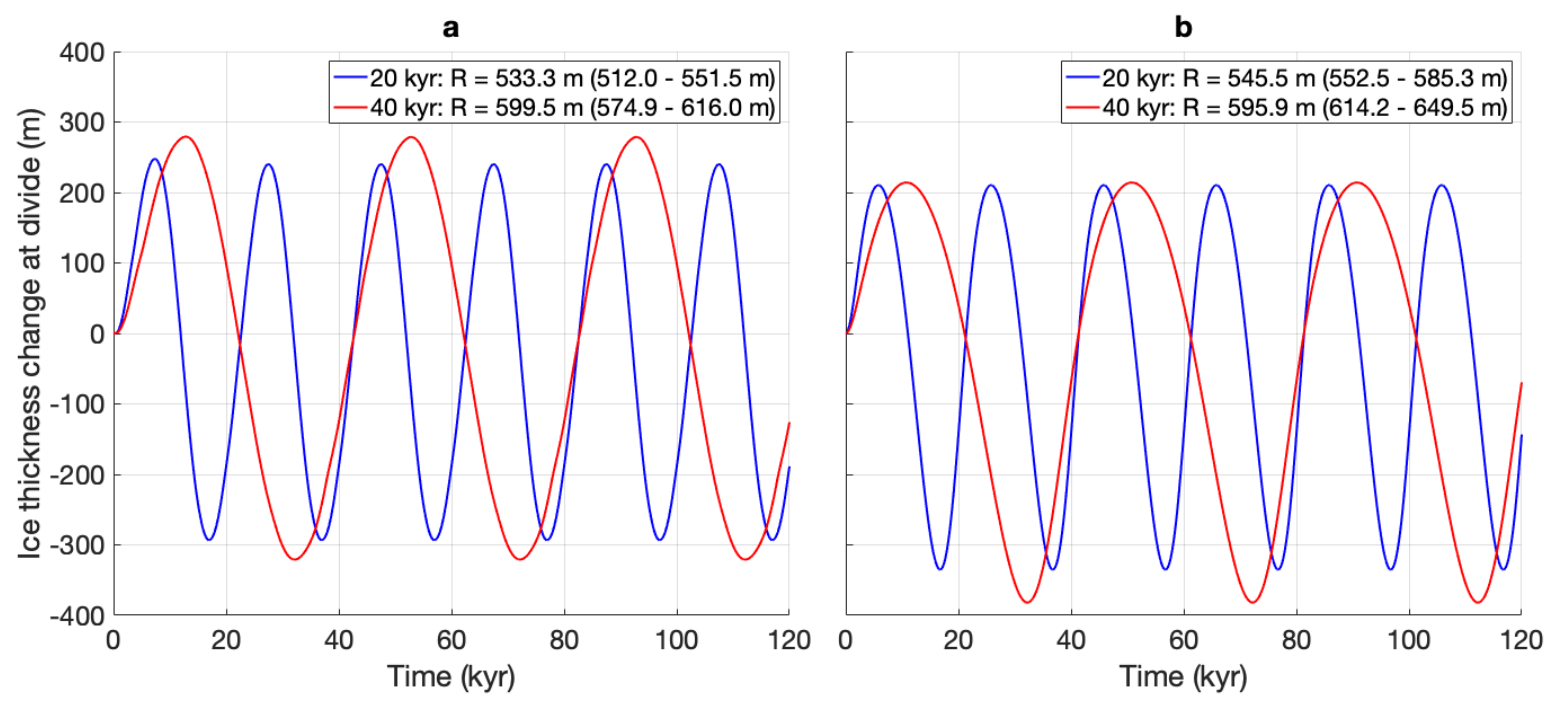

Figure 4: Ice thickness at the divide over time for the "glacial cycle" experiments from the first EISMINT intercomparison exercise, with a moving margin (panel a) and a fixed margin (panel $b$ ). The legends list the simulated glacial-interglacial difference $R$ for the last cycle, with the range of numbers reported by Huybrechts et al. (1996) listed between brackets for comparison. 

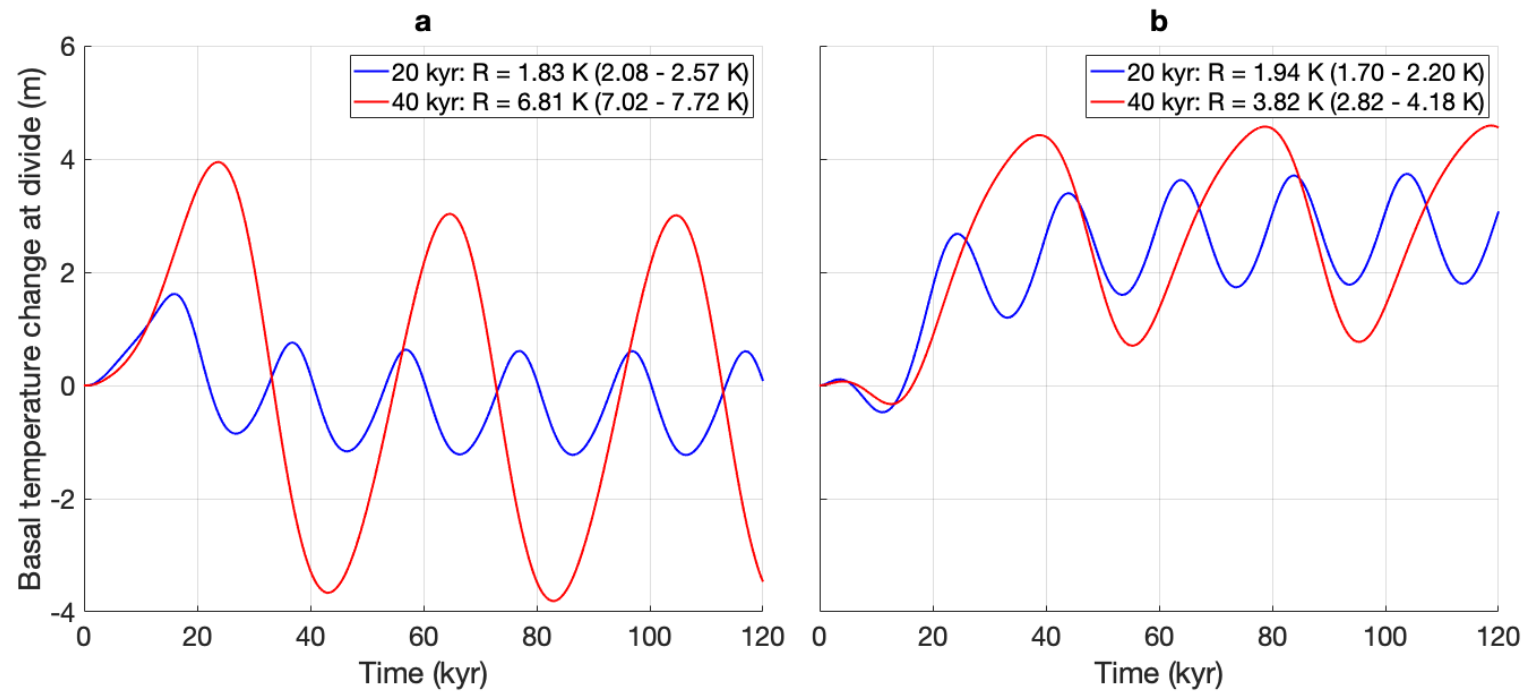

Figure 5: Ice temperature at the base of the ice divide, relative to the pressure melting point, over time for the "glacial cycle" experiments from the first EISMINT intercomparison exercise, with a moving margin (panel a) and a fixed margin (panel b). The legends list the simulated glacial-interglacial difference $R$ for the last cycle, with the range of numbers reported by Huybrechts et al. (1996) listed between brackets for comparison.

\subsection{ISMIP-HOM}

We verify our DIVA solver by performing the six experiments from the ISMIP-HOM intercomparison exercise (Pattyn et al., 2008), which are listed in Table 3. Experiments A-D consist of calculating instantaneous ice velocities for a given schematic geometry, experiment $\mathrm{E}$ entails calculating the velocity profile along a flowline of an actual glacier, and experiment $\mathrm{F}$ consists of determining the steady-state geometry of an idealised ice sheet. Experiments A-D describe an ice slab on a sloping bed, which is perturbed by small periodic perturbations to either the bed elevation or the bed friction. For each experiment, the horizontal scale of these perturbations is varied, ranging from $160 \mathrm{~km}$ to $5 \mathrm{~km}$, while the ice thickness is kept constant at $1 \mathrm{~km}$. A complete description of the experiments is given by Pattyn et al. (2008).

Table 3: The six different ISMIP-HOM experiments.

\section{Experiment Description}

\begin{tabular}{ll}
\hline A & Ice slab on a sloping bed with sinusoid bumps in both directions \\
B & Ice slab on a sloping bed with sinusoid bumps in one direction \\
C & Ice slab on a sloping bed with changing friction in both directions \\
D & Ice slab on a sloping bed with changing friction in one direction \\
E & Haut Glacier d'Arolla \\
F & Ice slab on a sloping bed with a single Gaussian bump
\end{tabular}


We performed all six experiments with IMAU-ICE v2.0, at all resolutions mentioned in the original ISMIP-HOM publication, with both the SIA/SSA and the DIVA ice dynamics. The results of experiment A are shown in Fig. 6. The SIA/SSA results become increasingly inaccurate as the spatial scale of the experiment decreases, with the velocities differing from the fullStokes solution by up to a factor ten. The results from the DIVA remain much closer to those of the higher-order and full-

5 Stokes models, in agreement with the findings reported by Goldberg (2011). Similar Figures for the other five experiments are provided in Appendix B; the results for these experiments are qualitatively similar.
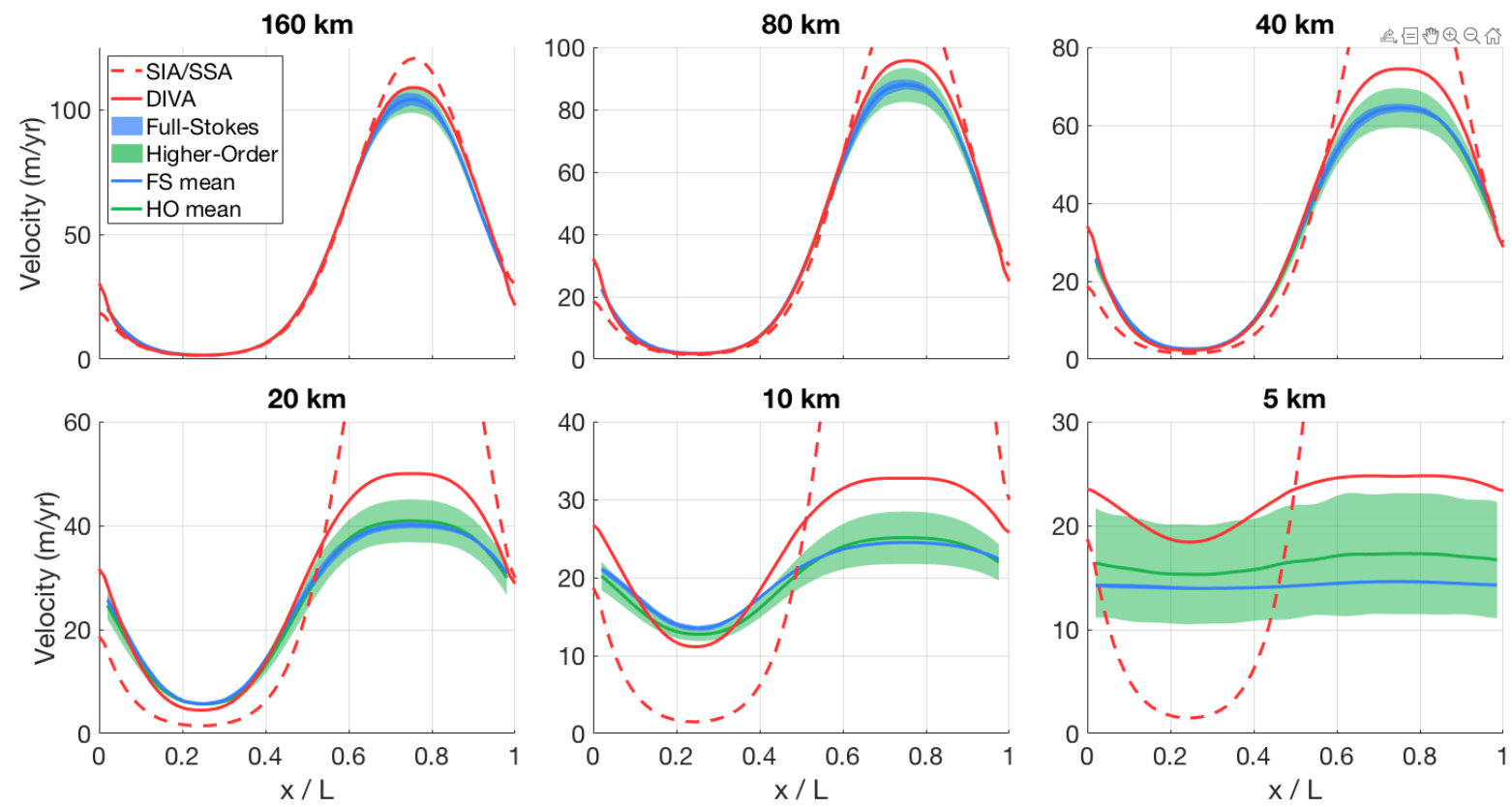

Figure 6: Modelled surface velocity transects for all versions of ISMIP-HOM experiment A, calculated with both the old hybrid SIA/SSA solver (red dashed line) and the new DIVA solver (red solid line). The results of the higher-order models (green) and the full-Stokes models (blue) that participated in ISMIP-HOM are shown for comparison.

\subsection{MISMIP}

The first MISMIP experiment (Pattyn et al., 2012) was extended by Pattyn (2017) from a 1-D flowline to a 2-D plan-view setting, describing a cone-shaped island with a uniform positive mass balance. This results in a circular ice sheet, surrounded by an infinite ice shelf. In the experiment, after $25-\mathrm{kyr}$ initialisation, the spatially uniform ice flow factor is subjected to 25 -

15 kyr step-wise decreases (increases), which result in an advancing (retreating) grounding line. The results of this experiment, as performed with IMAU-ICE at resolutions of 64, 32, and $16 \mathrm{~km}$, are shown in Fig. 7. As can be seen, grounding-line hysteresis decreases for higher resolution, and is smaller than the grid resolution for all three cases. 


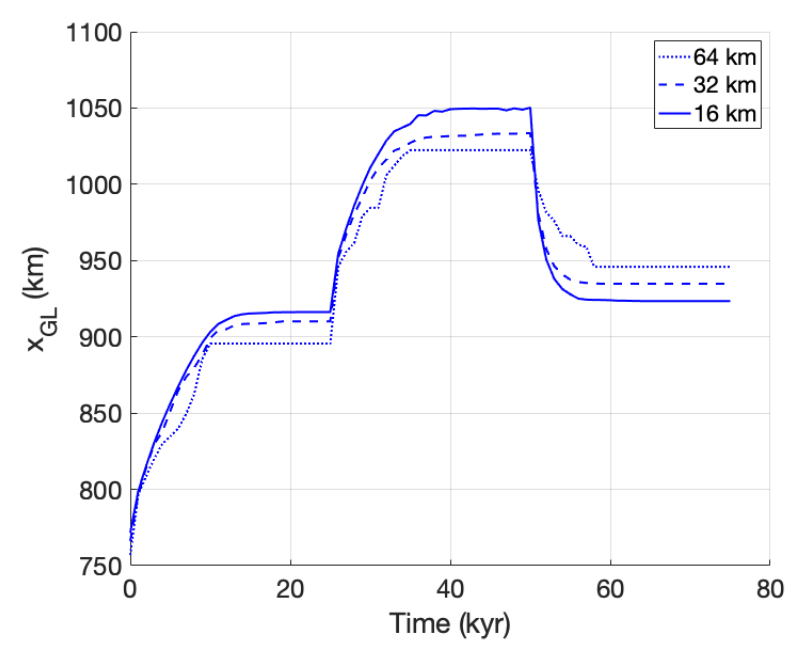

Figure 7: Grounding-line position over time in the MISMIP experiment at different resolutions. The first 25 kyr show the initialisation phase.

The $16-64 \mathrm{~km}$ resolutions we investigated here are much coarser than the values used by Feldmann et al. (2014) and Leguy

5 et al. (2021), and we find proportionally stronger grounding-line hysteresis. However, since we still find values that are smaller than the grid resolution, we deem these errors to be acceptably small in the context of palaeo-ice-sheet modelling.

\subsection{ABUMIP}

The Antarctic Buttressing Model Intercomparison Project (ABUMIP; Sun et al., 2020) investigates the dynamic response of the Antarctic ice sheet to the sudden disintegration of ice shelves, either by strongly increasing the sub-shelf melt (ABUM), or

10 by forcibly removing all floating ice in the model (ABUK). In both of these experiments, we chose to keep the SMB fixed to the present-day values simulated by the regional climate model RACMO2.3 (van Wessem et al., 2014), and mapped to a square grid using OBLIMAP 2.0 (Reerink et al., 2010, 2016). Before starting the 500-year simulation, we initialised the model with the observed present-day geometry from the Bedmachine Antarctica v1.0 dataset (Morlighem et al., 2019) and englacial temperatures according to the Robin solution, and spun it up by allowing it to relax for $500 \mathrm{yr}$. The spatially variable,

15 temporally constant geothermal heat flux is prescribed based on the data from Shapiro and Ritzwoller (2004). The results of both experiments, simulated at resolutions of 40,32, 20, and $16 \mathrm{~km}$, are shown in Figs. 8 (ABUM) and 9 (ABUK), together with the results from all the models from Sun et al. (2020), including IMAU-ICE v1.0. 

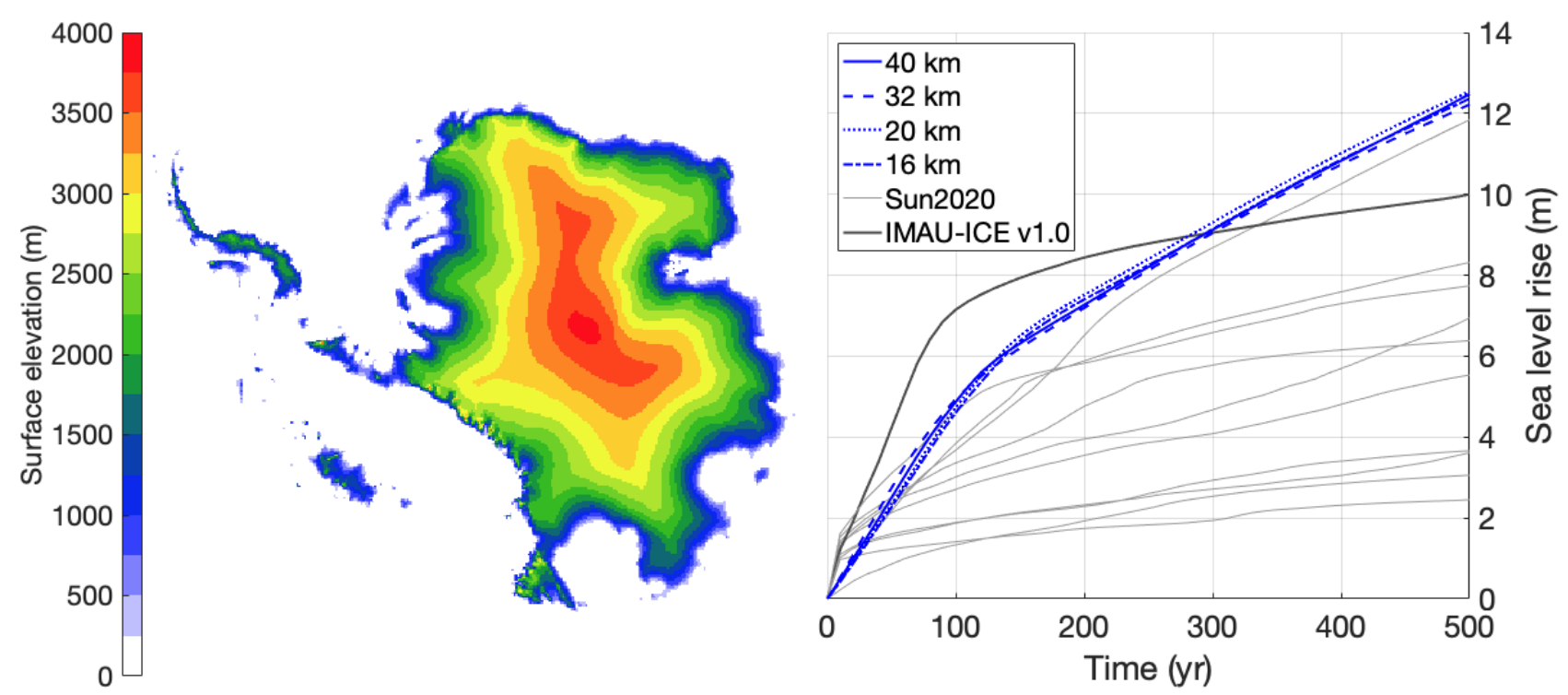

Figure 8: Surface elevation after 500 model years (left) and sea-level rise over time (right) at different model resolutions in the ABUM experiment, where the ice sheet is subjected to a uniform $400 \mathrm{~m} / \mathrm{yr} \mathrm{sub}$-shelf melt rate. Grey lines indicate the results of the models that participated in the ABUMIP model comparison (Sun et al., 2020); the results from IMAU-ICE v1.0 are shown by the dashed black line.

The ABUM and ABUK experiments yield nearly indistinguishable sea-level curves that do not significantly depend on model resolution. The modelled sea-level rise at $\mathrm{t}=500 \mathrm{yr}$ is $12.1-12.7 \mathrm{~m}$, just slightly exceeding the highest value of $11.8 \mathrm{~m}$ from Sun et al. (2020), which was generated by ELMER/ice for the ABUM experiment. In all experiments, the disintegration of shelves causes the West Antarctic Ice Sheet to collapse during the first $100-140$ model years, leading to about 6 meters of sea level rise. The East Antarctic Ice Sheet retreats at a steady pace throughout the entire simulation, producing the approximately linear curve between 150 and $500 \mathrm{yr}$. The rate of West Antarctic retreat during the first 100 - $140 \mathrm{yr}$ is within the range produced by the model ensemble of Sun et al. (2020), whereas the rate of East Antarctic retreat is the highest of all models except perhaps ELMER/ice.

15 Compared to IMAU-ICE v1.0, v2.0 produces a slower (faster) retreat in West (East) Antarctica, so that the sea-level rise at $\mathrm{t}$ $=500 \mathrm{yr}$ is now approximately $2 \mathrm{~m}$ higher. There are several differences between the two model versions that can explain these discrepancies, most importantly the approximation to the stress balance (hybrid SIA/SSA vs. DIVA), the treatment of the grounding line (flux condition vs. sub-grid friction scaling), and the spin-up procedure (10 kyr steady state vs. 500 yr relaxation). A more in-depth investigation of the effects of these choices on the modelled sea-level rise is ongoing, but is beyond the scope of this model description paper. 

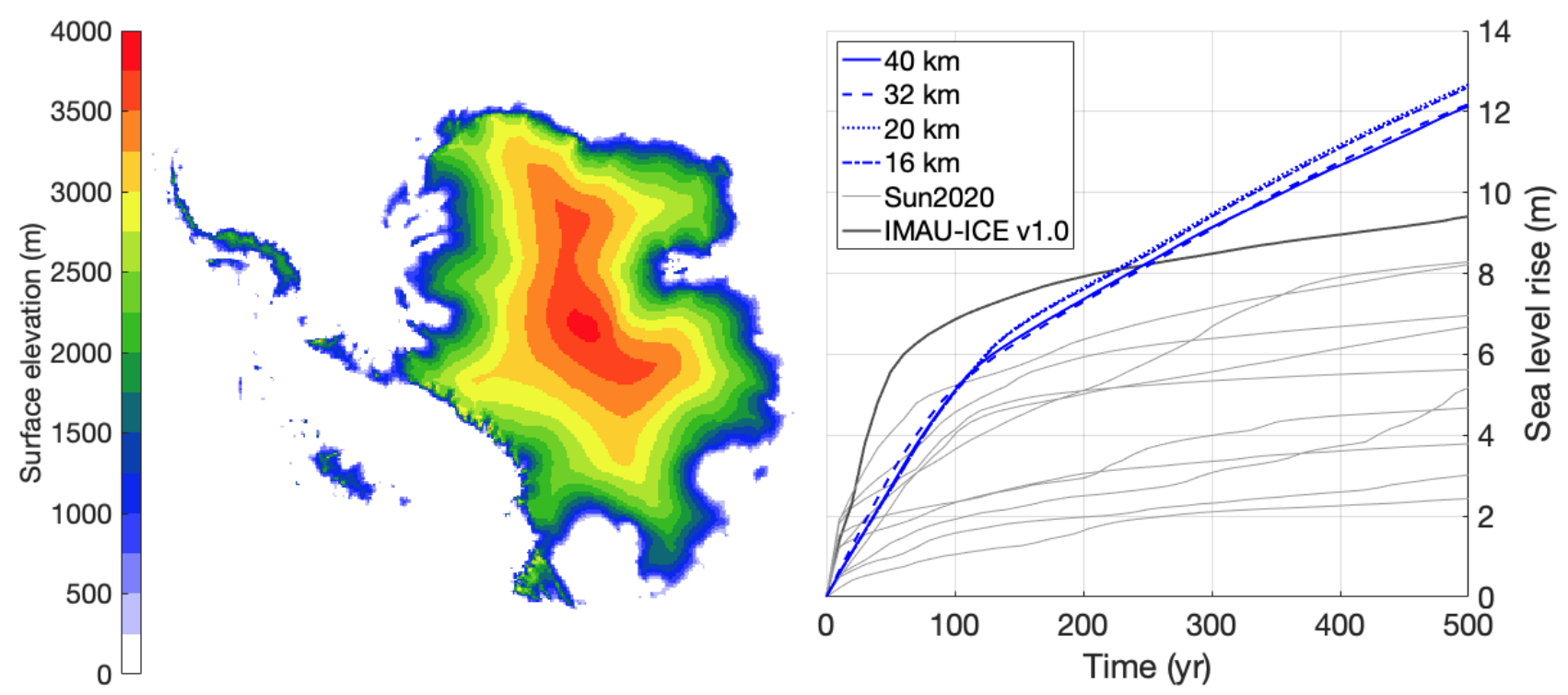

Figure 9: Surface elevation after 500 model years (left) and sea-level rise over time (right) at different model resolutions in the ABUK experiment, where all floating ice is removed. Grey lines indicate the results of the models that participated in the ABUMIP model comparison (Sun et al., 2020); the results from IMAU-ICE v1.0 are shown by the dashed black line.

\section{$5 \quad 5$ Conclusions and discussion}

\subsection{Current status and applicability}

We have presented version 2.0 of the vertically integrated ice-sheet model IMAU-ICE, which solves the DIVA approximation to the stress balance. We verified the numerical schemes used to solve the stress balance and integrate the ice thickness equation. These yield results that match several analytical solutions, or results from other ice-sheet models used in intercomparison experiments. Our findings match those of Goldberg (2011), showing that the DIVA remains physically accurate at much smaller resolutions than the hybrid SIA/SSA. We have also replaced the grounding-line flux condition used in IMAU-ICE v1.0 with a sub-grid scaling of the basal friction near the grounding line, resulting in improved numerical stability, while still achieving good results in terms of grounding-line hysteresis and resolution dependence in the MISMIP experiment.

IMAU-ICE v2.0 can be used both for future projections and for palaeo-applications, but generally provides more support for the latter. With a minimum of effort, the user can change the external configuration file to choose between different (palaeo)climatic and topographic conditions, geological periods, ice, methods of forcing, ice-dynamical approximations, and mass balance parameterisations. This ensures easy reproduction of results, as well as a smooth workflow. The climate component of the model is particularly flexible; although previous palaeoglaciogical studies using ANICE/IMAU-ICE all used the same HadCM3 output (Singarayer and Valdes, 2010) to construct the climate matrix, the matrix method can in principle be applied 
to output from any GCM, and IMAU-ICE v2.0 has been designed to easily accommodate different GCM data. The climate data needs to be provided on a regular, global lon/lat-grid, and the projection to the ice-model grid is automatically performed internally. Taking advantage of this ease-of-use, IMAU-ICE is currently being used in different palaeoglaciological studies. One example concerns the evolution of the Antarctic ice sheet during the warm Miocene (Stap et al., in review), using climate data from the GENESIS GCM, and an Antarctic palaeotopographic reconstruction. Another currently ongoing project involves an ensemble of simulations of the last glacial cycle, forced with all of the GCMs that participated in PMIP3 (Scherrenberg et al., in prep.).

Since about 2018, IMAU-ICE has also been used for simulations of near-future ice-sheet evolution. New features introduced 10 in the code overhaul from ANICE to IMAU-ICE, including improved high-resolution support, prescribed climate/SMBforcing, improved grounding-line dynamics, and easy restarting (to facilitate different spin-up strategies) have greatly improved the model's usability and applicability in such settings. However, compared to ice-sheet models that have been developed specifically for this purpose, IMAU-ICE still has relatively simplistic representations of physical processes such as glacial rheology and damage, subglacial hydrology and basal sliding, and englacial stresses in areas with high aspect ratios.

15 While this makes it feasible to perform large ensemble simulations at relatively coarse resolutions, it means the users must take more caution when interpreting model results on sub-basin spatial scales.

IMAU-ICE v2.0 is partly parallelised; the matrix equations representing the DIVA (the most computationally expensive part of the model by far) are solved using the PETSc library (Balay et al., 2021), whereas all other routines are parallelised using

20 MPI shared memory. This is a compromise between performance and user-friendliness; while the code structure and syntax of MPI shared memory are very similar to non-parallelised code, it is not easy to extend this to a fully distributed implementation. Conversely, PETSc is highly scalable, but since it is less friendly to novice ice-sheet modellers, its use has been limited to the velocity solver. As a result of this compromise, IMAU-ICE can be run only on the maximum number of processors on the user's hardware system that can access the same physical memory chip (usually 16, 24, or 32 cores on typical scientific computation systems). For the long ( $>100,000 \mathrm{yr})$, low-resolution $(\sim 40 \mathrm{~km})$ palaeo-ice-sheet simulations, and short $(<1,000$ yr), medium-resolution $(\sim 16 \mathrm{~km})$ future projections that we intend to use the model for, this results in computation times that are typically short enough to run the model overnight.

\subsection{Future research}

In their recent study, Leguy et al. (2021) demonstrated the strong effect of sub-grid parameterisations of sub-shelf melt on 30 grounding-line dynamics. Preliminary experiments with IMAU-ICE showed similar results in the ABUMIP experiment, where the sea-level rise at the end of the 500-yr simulation could differ by as much as a factor two depending on the choice of subgrid scheme. The NMP and PMP schemes also resulted in a modelled sea-level rise that depended significantly on the grid 
https://doi.org/10.5194/gmd-2021-352

Preprint. Discussion started: 4 January 2022

(C) Author(s) 2022. CC BY 4.0 License.

(c) (i)

resolution. A more in-depth study of this phenomenon and how it relates to e.g. the choice of stress balance approximation, sliding law, and model spin-up procedure, is currently underway, and will be reported in a future publication.

The parameterisations of sub-shelf melt and calving currently used in IMAU-ICE are overly simplistic. We are currently

5 working on a thorough overhaul of these model components, which will include an implementation of the PICO model (Reese et al., 2018b), as well as a more elaborate plume model (Lazeroms et al., 2018).

\section{Code and data availability}

The source code of IMAU-ICE is maintained on Github at https://github.com/IMAU-paleo/IMAU-ICE. The exact version used in this study (including makefiles, compiling scripts, run scripts, config files for all the simulations presented here, and

10 Matlab scripts for creating the figures) is archived on Zenodo.org (doi: 10.5281/zenodo.5796152).

Author contributions. CJB wrote the code for the new model version, with contributions from LBS and HG. CJB performed the experiments and analysed the data. CJB wrote the draft of the manuscript; all authors contributed to the final version.

15 Acknowledgements. We are very grateful to Alex Robinson for his help in setting up the DIVA solver, and to Lars Zipf for his insightful comments on grounding-line dynamics.

Competing interests. The authors declare that they have no competing interests.

20 Financial support. This publication was supported by PROTECT. This project has received funding from the European Union's Horizon 2020 research and innovation programme under grant agreement no. 869304 (PROTECT; [article number will be assigned upon acceptance for publication!]). The use of supercomputer facilities was sponsored by NWO Exact and Natural Sciences. Model runs were performed on the Dutch National Supercomputer Cartesius. we would like to acknowledge SurfSARA Computing and Networking Services for their support. L.B. Stap is funded by the Dutch Research Council (NWO),

25 through VENI grant VI.Veni.202.031. Heiko Goelzer has received funding from the programme of the Netherlands Earth System Science Centre (NESSC), financially supported by the Dutch Ministry of Education, Culture and Science (OCW), under grant no. 024.002.001 and from the Research Council of Norway under projects INES (270061) and KeyClim (295046). High-performance computing and storage resources were provided by the Norwegian infrastructure for computational science through projects NN9560K, NN9252K, NS9560K, NS9252K and NS5011K. 


\section{Appendix A - Discretisation}

The ice-dynamical equations in IMAU-ICE are discretised using staggered Arakawa grids (see Fig. A1), a common practice in ice-sheet modelling. Material properties such as ice thickness, flow factor, and englacial temperature are defined on the regular Arakawa-A grid, while the horizontal velocity components $u, v$ are defined on the staggered Arakawa-Cx/Cy grids.

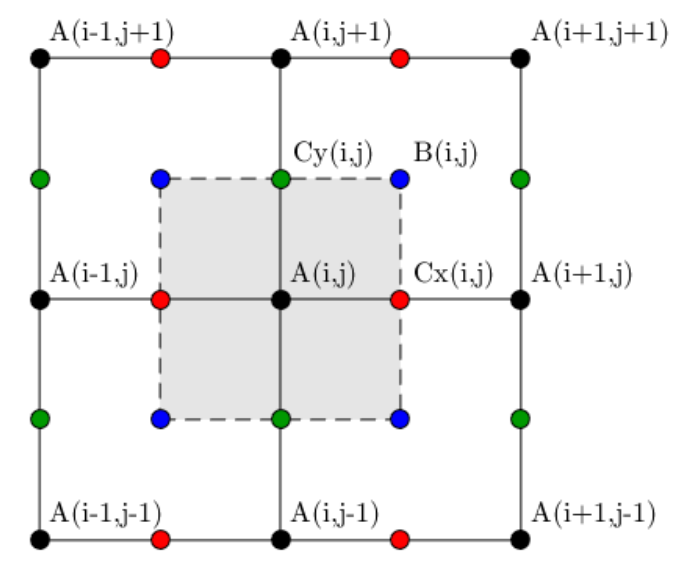

Figure A1: The four Arakawa grids: regular (A; black), staggered in the x-direction (Cx; red), staggered in the y-direction (Cy; green), and staggered in both directions (B; blue).

Following the approach from Yelmo (Robinson et al., 2020), Eqs. 1 are discretised by defining all derivatives as finite differences between the nearest half-grid points. Since the velocity $u$ is defined on the Cx-grid, the first outer derivative $\frac{\partial}{\partial x}[\ldots]$

10 is defined as the difference between the neighbouring A-grid points, while the second outer derivative $\frac{\partial}{\partial y}[\ldots]$ is defined as the difference between the neighbouring B-grid points:

$$
\begin{gathered}
\frac{\left[2 \bar{\eta} H\left(2 u_{x}+v_{y}\right)\right]_{A}^{i+1, j}-\left[2 \bar{\eta} H\left(2 u_{x}+v_{y}\right)\right]_{A}^{i, j}}{\Delta x}+\frac{\left[\bar{\eta} H\left(u_{y}+v_{x}\right)\right]_{B}^{i, j}-\left[\bar{\eta} H\left(u_{y}+v_{x}\right)\right]_{B}^{i, j-1}}{\Delta y}-\beta_{e f f, C x}^{i, j} u_{C x}^{i, j} \\
=-\tau_{d, x, C x}^{i, j} .
\end{gathered}
$$

The inner derivatives $u_{x}, u_{y}, v_{x}, v_{y}$ too, are discretised with respect to the nearest half-grid points, which are the $\mathrm{Cx}$ and Cygrids where the velocities are defined:

$$
\begin{gathered}
u_{x, A}^{i+1, j}=\frac{u_{C x}^{i+1, j}-u_{C x}^{i, j}}{\Delta x}, u_{x, A}^{i, j}=\frac{u_{C x}^{i, j}-u_{C x}^{i-1, j}}{\Delta x}, u_{y, B}^{i, j}=\frac{u_{C x}^{i, j+1}-u_{C x}^{i, j}}{\Delta y}, u_{y, B}^{i, j-1}=\frac{u_{C x}^{i, j}-u_{C x}^{i, j-1}}{\Delta y}, \\
v_{y, A}^{i+1, j}=\frac{v_{C y}^{i+1, j}-v_{C y}^{i+1, j-1}}{\Delta y}, v_{y, A}^{i, j}=\frac{v_{C y}^{i, j}-v_{C y}^{i, j-1}}{\Delta y}, v_{x, B}^{i, j}=\frac{v_{C y}^{i+1, j}-v_{C y}^{i, j}}{\Delta x}, v_{x, B}^{i, j-1}=\frac{v_{C y}^{i+1, j-1}-v_{C y}^{i, j-1}}{\Delta x} .
\end{gathered}
$$

Substituting Eqs. A3 into Eq. A2 yields: 


$$
\begin{gathered}
\frac{2(\bar{\eta} H)_{A}^{i+1, j}}{\Delta x}\left[2 \frac{u_{C x}^{i+1, j}-u_{C x}^{i, j}}{\Delta x}+\frac{v_{C y}^{i+1, j}-v_{C y}^{i+1, j-1}}{\Delta y}\right] \\
-\frac{2(\bar{\eta} H)_{A}^{i, j}}{\Delta x}\left[2 \frac{u_{C x}^{i, j}-u_{C x}^{i-1, j}}{\Delta x}+\frac{v_{C y}^{i, j}-v_{C y}^{i, j-1}}{\Delta y}\right] \\
+\frac{(\bar{\eta} H)_{B}^{i, j}}{\Delta y}\left[\frac{u_{C x}^{i, j+1}-u_{C x}^{i, j}}{\Delta y}+\frac{v_{C y}^{i+1, j}-v_{C y}^{i, j}}{\Delta x}\right] \\
-\frac{(\bar{\eta} H)_{B}^{i, j-1}}{\Delta y}\left[\frac{u_{C x}^{i, j}-u_{C x}^{i, j-1}}{\Delta y}+\frac{v_{C y}^{i+1, j-1}-v_{C y}^{i, j-1}}{\Delta x}\right] \\
-\beta_{e f f, C x}^{i, j} u_{C x}^{i, j}=-\tau_{d, x, C x}^{i, j}
\end{gathered}
$$

Assuming that $\Delta x=\Delta y=\Delta$ (which is the case in IMAU-ICE), multiplying both sides by $\Delta^{2}$, and defining the product term $N=\bar{\eta} H$, Eq. A4 can be rearranged to read:

$$
\begin{gathered}
u_{C x}^{i, j}\left(-4 N_{A}^{i+1, j}-4 N_{A}^{i, j}-N_{B}^{i, j}-N_{B}^{i, j-1}-\Delta^{2} \beta_{e f f, C x}^{i, j}\right) \\
+u_{C x}^{i+1, j}\left(4 N_{A}^{i+1, j}\right)+u_{C x}^{i-1, j}\left(4 N_{A}^{i, j}\right)+u_{C x}^{i, j+1}\left(N_{B}^{i, j}\right)+u_{C x}^{i, j-1}\left(N_{B}^{i, j-1}\right) \\
+v_{C y}^{i, j}\left(-2 N_{A}^{i, j}-N_{B}^{i, j}\right)+v_{C y}^{i+1, j}\left(2 N_{A}^{i+1, j}+N_{B}^{i, j}\right)+v_{C y}^{i, j}\left(2 N_{A}^{i, j}+N_{B}^{i, j-1}\right)+v_{C y}^{i+1, j}\left(-2 N_{A}^{i+1, j}-N_{B}^{i, j-1}\right) \\
=-\Delta^{2} \tau_{d, x, C x}^{i, j} .
\end{gathered}
$$

Eq. A5, together with the equivalent representation of the second DIVA equation, can be represented by a sparse matrix equation (with 9 non-zero elements per row), which can be solved by any desired matrix solving algorithm (the default in 5 IMAU-ICE is PETSc, though a generic SOR-solver can alternatively be used). The strain rates $u_{x}, u_{y}, v_{x}, v_{y}$, the effective viscosity $\eta$, and the product term $N$ are all calculated on the regular A-grid; $N_{B}$ is obtained by staggering $N_{A}$. The sliding term $\beta_{\text {eff }}$ is calculated on the A-grid, then staggered to the $\mathrm{Cx} / \mathrm{Cy}$-grids, where it is scaled with the grounded fraction (which is calculated directly on the $\mathrm{Cx} / \mathrm{Cy}$-grids). 


\section{Appendix B - ISMIP-HOM results}
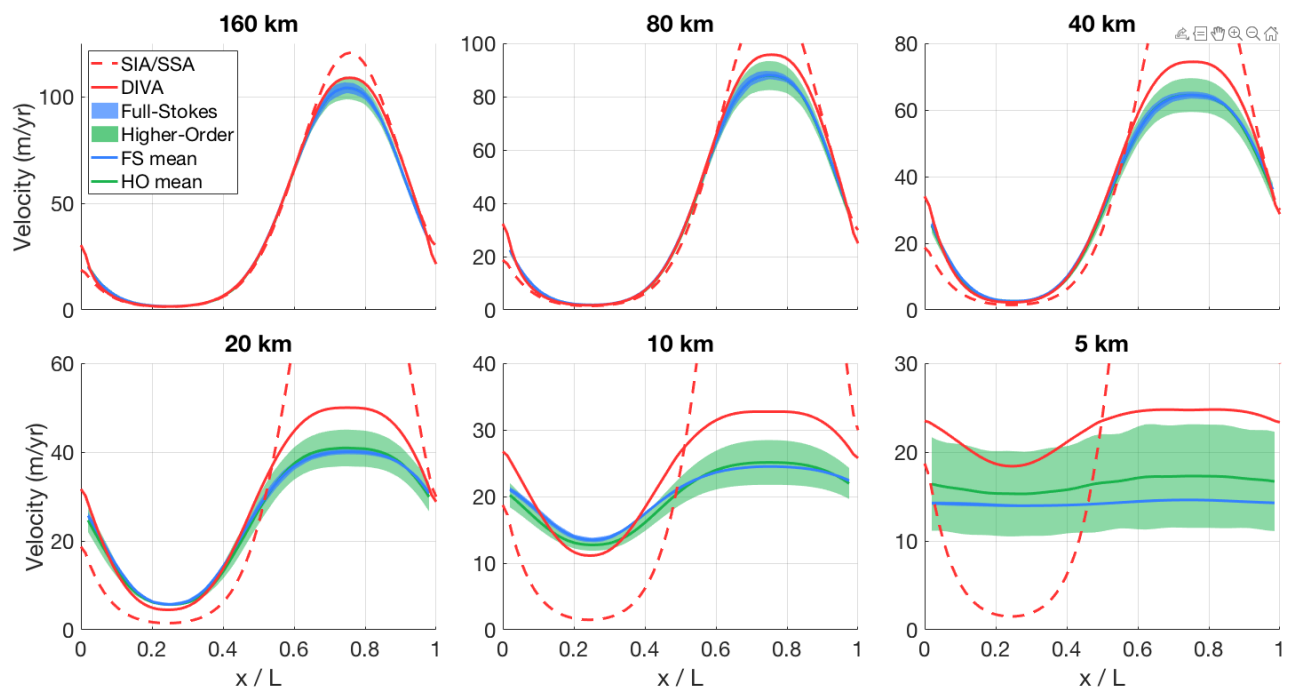

Figure B1: Modelled surface velocity transects for all versions of ISMIP-HOM experiment A (infinite ice slab on a sloping bed with sinusoid bumps in both directions), calculated with both the old hybrid SIA/SSA solver (red dashed line) and the new DIVA solver (red solid line). The results of the higher-order models (green) and the full-Stokes models (blue) that participated in ISMIP-HOM are shown for comparison.
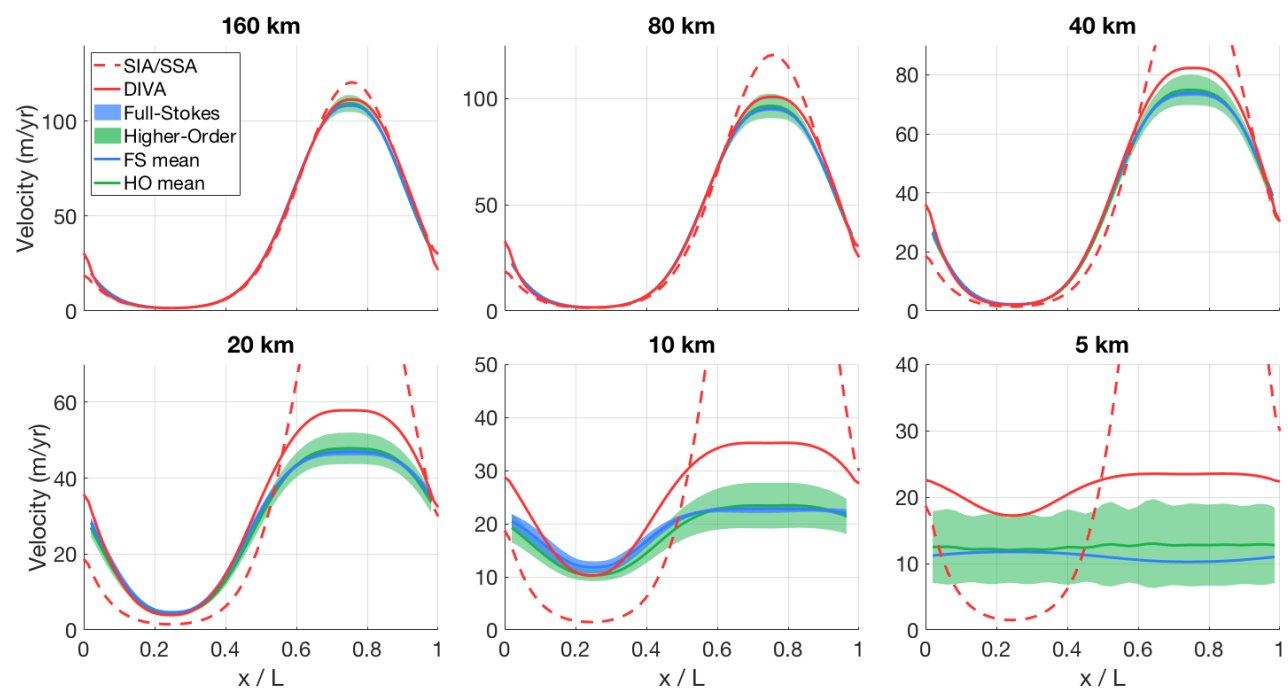

Figure B2: Modelled surface velocity transects for all versions of ISMIP-HOM experiment B (infinite ice slab on a sloping bed with sinusoid bumps in one direction), calculated with both the old hybrid SIA/SSA solver (red dashed line) and the new DIVA solver (red solid line). The results of the higher-order models (green) and the full-Stokes models (blue) that participated in ISMIP-HOM are shown for comparison. 

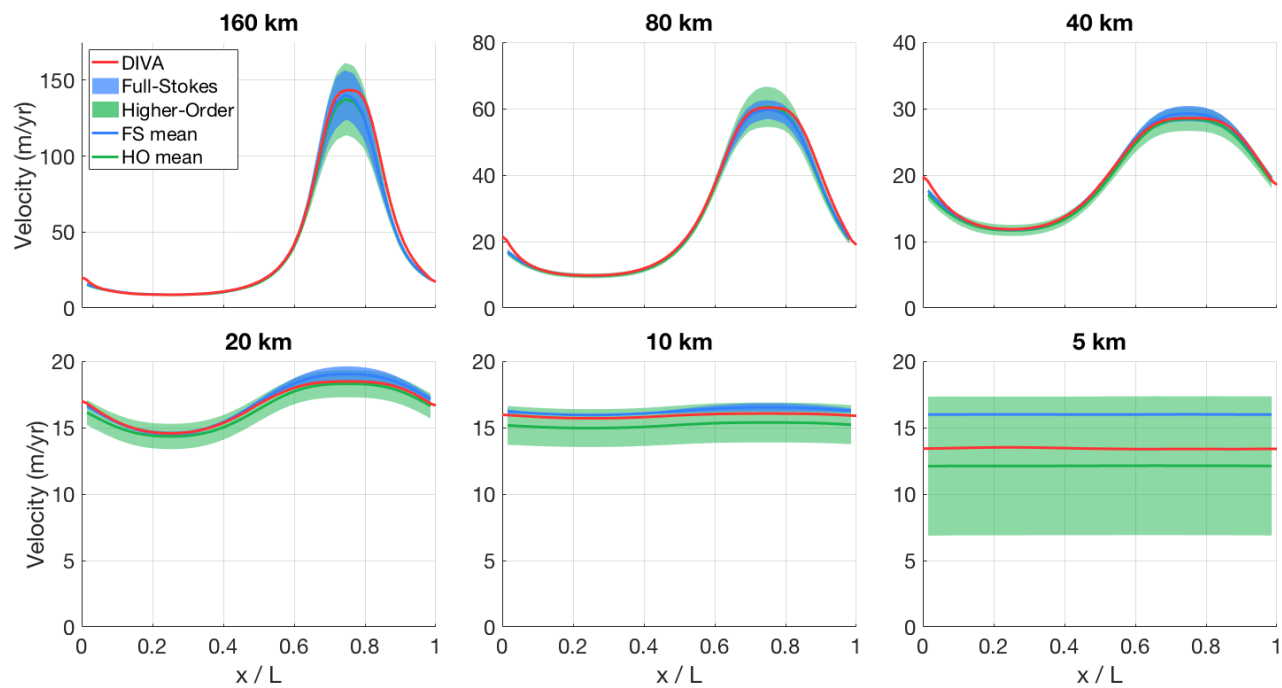

Figure B3: Modelled surface velocity transects for all versions of ISMIP-HOM experiment C (infinite ice slab on a sloping bed with oscillating friction in both directions), calculated with both the old hybrid SIA/SSA solver (red dashed line) and the new DIVA solver (red solid line). The results of the higher-order models (green) and the full-Stokes models (blue) that participated in ISMIP-HOM are shown for comparison.
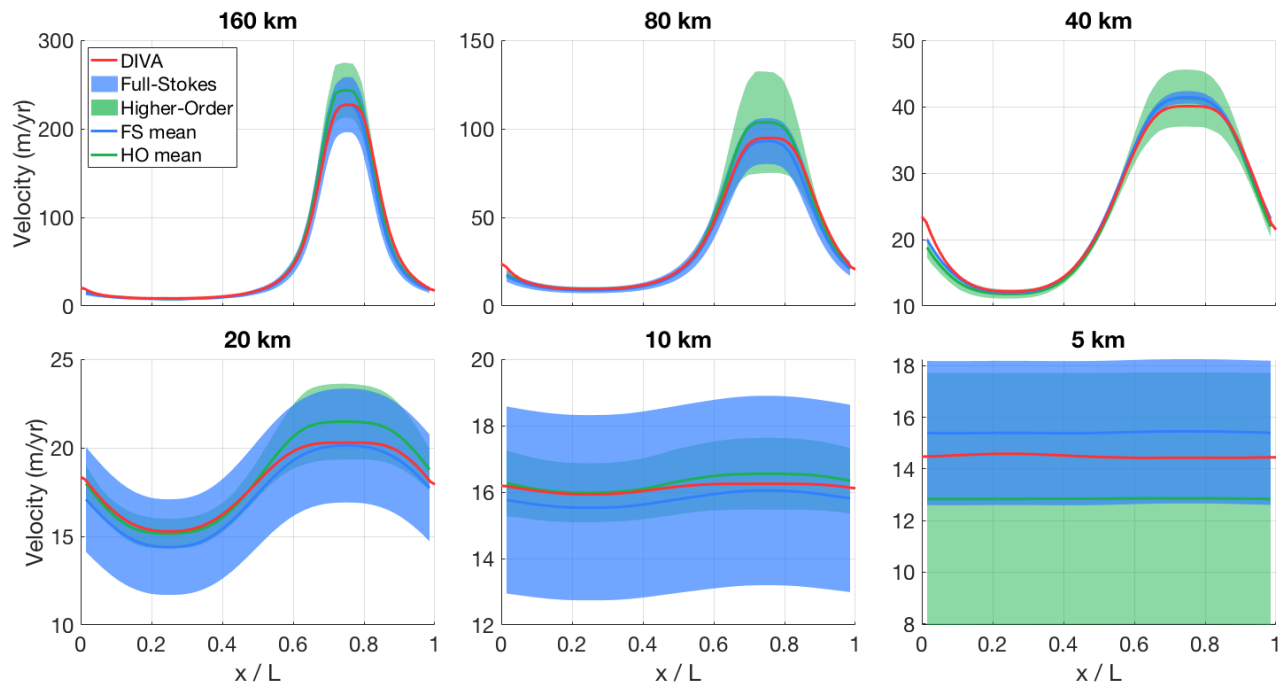

Figure B4: Modelled surface velocity transects for all versions of ISMIP-HOM experiment D (infinite ice slab on a sloping bed with oscillating friction in one direction), calculated with both the old hybrid SIA/SSA solver (red dashed line) and the new DIVA solver (red solid line). The results of the higher-order models (green) and the full-Stokes models (blue) that participated in ISMIP-HOM are shown for comparison. 

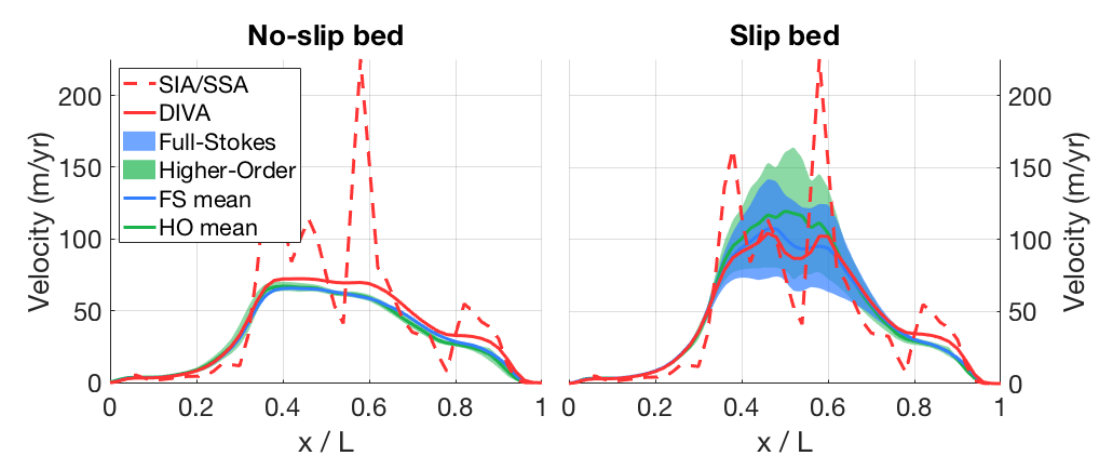

Figure B5: Modelled surface velocity transects for both versions of ISMIP-HOM experiment E (Haut Glacier d'Arolla, with and without a slippery bed region), calculated with both the old hybrid SIA/SSA solver (red dashed line) and the new DIVA solver (red solid line). The results of the higher-order models (green) and the full-Stokes models (blue) that participated in ISMIP-HOM are shown for comparison.
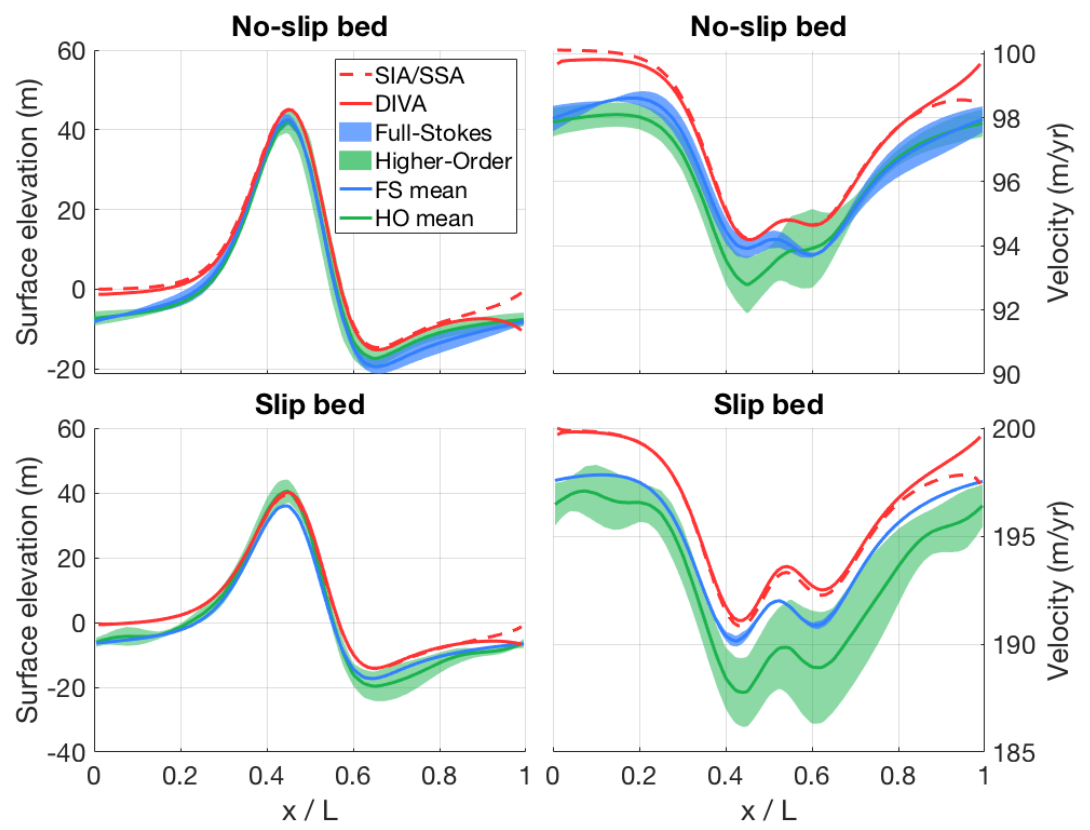

Figure B6: Modelled surface elevation and velocity transects for both versions of ISMIP-HOM experiment $\mathrm{F}$ (infinite ice slab on a sloping bed with a single Gaussian bump, with and without a slippery bed), calculated with both the old hybrid SIA/SSA solver (red dashed line) and the new DIVA solver (red solid line). The results of the higher-order models (green) and the full-Stokes models (blue) that participated in ISMIP-HOM are shown for comparison. 
https://doi.org/10.5194/gmd-2021-352

Preprint. Discussion started: 4 January 2022

(c) Author(s) 2022. CC BY 4.0 License.

(c) (i)

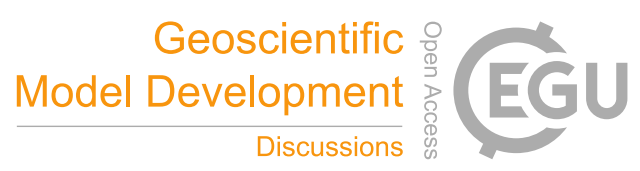

\section{References}

Balay, S., Abhyankar, S., Adams, M. F., Brown, J., Brune, P., Buschelman, K., Dalcin, L., Dener, A., Eijkhout, V., Gropp, W. D., Kaushik, D., Knepley, M. G., May, D. A., Curfman McInnes, L., Tran Mills, R., Munson, T., Rupp, K., Sanan, P., Smith, B. F., Zampini, S., and Zhang, H.: PETSc Users Manual, ANL-95/11 - Revision 3.15, Argonne National Laboratory, 2021

5 Berends, C. J., de Boer, B., and van de Wal, R. S. W.: Application of HadCM3@Bristolv1.0 simulations of paleoclimate as forcing for an ice-sheet model, ANICE2.1: set-up and benchmark experiments, Geoscientific Model Development 11, 46574675, 2018

Berends, C. J., de Boer, B., Dolan, A. M., Hill, D. J., and van de Wal, R. S. W.: Modelling ice sheet evolution and atmospheric CO2 during the Late Pliocene, Climate of the Past 15, 1603-1619, 2019

10 Berends, C. J., de Boer, B., and van de Wal, R. S. W.: Reconstructing the evolution of ice sheets, sea level, and atmospheric CO2 during the past 3.6 million years, Climate of the Past 17, 361-377, 2021a

Berends, C. J., Goelzer, H., and van de Wal, R. S. W.: The Utrecht Finite Volume Ice-Sheet Model: UFEMISM (version 1.0), Geoscientific Model Development 14, 2443-2470, 2021b

Bintanja, R. and van de Wal, R. S. W.: North American ice-sheet dynamics and the onset of 100,000-year glacial cycles,

15 Nature 454, 869-872, 2008

de Boer, B., van de Wal, R., Lourens, L. J., Bintanja, R., and Reerink, T. J.: A continuous simulation of global ice volume over the past 1 million years with 3-D ice-sheet models, Climate Dynamics 41, 1365-1384, 2013

de Boer, B., Stocchi, P., and van de Wal, R.: A fully coupled 3-D ice-sheet-sea-level model: algorithm and applications, Geoscientific Model Development 7, 2141-2156, 2014

20 Bueler, E., Lingle, C. S., Kallen-Brown, J. A., Covey, D. N., and Bowman, L. N.: Exact solutions and verification of numerical models for isothermal ice sheets, Journal of Glaciology 51, 291-306, 2005

Bradley, S. L., Reerink, T. J., van de Wal, R. S. W., and Helsen, M. M.: Simulation of the Greenland Ice Sheet over two glacial-interglacial cycles: investigating a sub-ice-shelf melt parameterization and relative sea level forcing in an ice-sheetice-shelf model, Climate of the Past 14, 619-635, 2018

25 Cheng, G., Lötstedt, P., and van Sydow, L.: Accurate and stable time stepping in ice sheet modeling, Journal of Computational Physics 329, 29-47, 2016

Cuzzone, J. K., Schlegel, N.-J., Morlighem, M., Larour, E., Briner, J. P., Seroussi, H., and Caron, L.: The impact of model resolution on the simulated Holocene retreat of the southwestern Greenland ice sheet using the Ice Sheet System Model (ISSM), The Cryosphere 13, 879-893, 2019

30 Edwards, T. L., Nowicki, S., Marzeion, B., Hock, R., Goelzer, H., Seroussi, H., Jourdain, N. C., Slater, D. A., Turner, F. A., Smith, C. J., McKenna, C. M., Simon, E. G., Abe-Ouchi, A., Gregory, J. M., Larour, E., Lipscomb, W. H., Payne, A. J., Shepherd, A., Agosta, C., Alexander, P., Albrecht, T., Anderson, B., Asay-Davis, X. S., Aschwanden, A., Barthel, A., Bliss, A., Calov, R., Chambers, C., Champollion, N., Choi, Y., Cullather, R., Cuzzone, J. K., Dumas, C., Felikson, D., Fettweis, X., 
Fujita, K., Galton-Fenzi, B. K., Gladstone, R. M., Golledge, N. R., Greve, R., Hattermann, T., Hoffman, M. J., Humbert, A., Huss, M., Huybrechts, P., Immerzeel, W., Kleiner, T., Kraaijenbrink, P., Le Clec'h, S., Lee, V., Leguy, G. R., Little, C. M., Lowry, D. P., Malles, J.-H., Martin, D. F., Maussion, F., Morlighem, M., O'Neill, J. F., Nias, I., Pattyn, F., Pelle, T., Price, S. F., Quiquet, A., Radic, V., Reese, R., Rounce, D. R., Rückamp, M., Sakai, A., Shafer, C., Schlegel, N.-J., Shannon, S., Smith, 5 R. S., Straneo, F., Sun, S., Tarasov, L., Trusel, L. D., Van Breedam, J., van de Wal, R. S. W., van den Broeke, M. R., Winkelmann, R., Zekollari, H., Zhao, C., Zhang, T., and Zwinger, T.: Projected land ice contributions to twenty-first-century sea level rise, Nature 593, 74-82, 2021

Feldmann, J., Albrecht, T., Khroulev, C., Pattyn, F., and Levermann, A.: Resolution-dependent performance of grounding line motion in a shallow model compared with a full-Stokes model according to the MISMIP3d intercomparison, Journal of

10 Glaciology 60, 353-360, 2014

Fettweis, X., Hofer, S., Krebs-Kanzow, U., Amory, C., Aoki, T., Berends, C. J., Born, A., Box, J. E., Delhasse, A., Fujita, K., Gierz, P., Goelzer, H., Hanna, E., Hashimoto, A., Huybrechts, P., Kapsch, M.-L., King, M. D., Kittel, C., Lang, C., Langen, P. L., Lenaerts, J. T. M., Liston, G. E., Lohmann, G., Mernild, S. H., Mikolajewicz, U., Modali, K., Mottram, R. H., Niwano, M., Noël, B. P. Y., Ryan, J. C., Smith, A., Streffing, J., Tedesco, M., van de Berg, W. J., van den Broeke, M. R., van de Wal, 15 R. S. W., van Kampenhout, L., Wilton, D., Wouters, B., Ziemen, F., and Zolles, T.: GrSMBMIP: intercomparison of the modelled 1980-2012 surface mass balance over the Greenland Ice Sheet, The Cryosphere 14, 3935-3958, 2020

B. Fox-Kemper, H. T. Hewitt, C. Xiao, G. Adalgeirsdottir, S.S. Drijfhout, T.L. Edwards, N.R. Golledge, M. Hemer, R.E. Kopp, G. Krinner, A. Mix, D. Notz, S. Nowicki, I.S. Nurhati, L. Ruiz, J-B. Sallée, A.B. A. Slangen, Y. Yu, Ocean, Cryospher and Sea Level Change. Climate Change 2021: The Physical Science Basis. Contribution of Working Group 1 to the Sixth

20 Assessment Report of the Intergovernmental Panel on Climate change [Masson-Delmotte, V., P. Zhai, A. Pirani, S.L. Connors, C.Péan, S. Berger, N. Caud, Y. Chen, L. Goldfarb, M.I. Gomis, M. Huang, K. Leitzell, E. Lonnoy, J.B.R. Matthes, T.K. Maycock, T. Waterfield, O. Yelekci, R. Yu and B. Zhou (eds.)] (2021).

Goelzer, H., Nowicki, S., Edwards, T. L., Beckley, M., Abe-Ouchi, A., Aschwanden, A., Calov, R., Gagliardini, O., GilletChaulet, F., Golledge, N. R., Gregory, J. M., Greve, R., Humbert, A., Huybrechts, P., Kennedy, J. H., Larour, E., Lipscomb,

25 W. H., Le Clec'h, S., Lee, V., Morlighem, M., Pattyn, F., Payne, A. J., Rodehacke, C., Rückamp, M., Saito, F., Schlegel, N., Seroussi, H., Shepherd, A., Sun, S., van de Wal, R. S. W., and Ziemen, F.: Design and results of the ice sheet model initialisation experiments initMIP-Greenland: an ISMIP6 intercomparison, The Cryosphere 12, 1433-1460, 2018

Goelzer, H., Nowicki, S., Payne, A. J., Larour, E., Seroussi, H., Lipscomb, W. H., Gregory, J. M., Abe-Ouchi, A., Shepherd, A., Simon, E. G., Agosta, C., Alexander, P., Aschwanden, A., Barthel, A., Calov, R., Chambers, C., Choi, Y., Cuzzone, J. K.,

30 Dumas, C., Edwards, T. L., Felikson, D., Fettweis, X., Golledge, N. R., Greve, R., Humbert, A., Huybrechts, P., Le Clec'h, S., Lee, V., Leguy, G. R., Little, C. M., Lowry, D. P., Morlighem, M., Nias, I., Quiquet, A., Rückamp, M., Schlegel, N.-J., Slater, D. A., Smith, R. S., Straneo, F., Tarasov, L., van de Wal, R. S. W., and van den Broeke, M. R.: The future sea-level contribution of the Greenland ice sheet: a multi-model ensemble study of ISMIP6, The Cryosphere 14, 3071-3096, 2020a 
https://doi.org/10.5194/gmd-2021-352

Preprint. Discussion started: 4 January 2022

(c) Author(s) 2022. CC BY 4.0 License.

Goelzer, H., Noël, B. P. Y., Edwards, T. L., Fettweis, X., Gregory, J. M., Lipscomb, W. H., van de Wal, R. S. W., and van den Broeke, M. R.: Remapping of Greenland ice sheet surface mass balance anomalies for large ensemble sea-level change projections, The Cryosphere 14, 1747-1762, 2020b

Goldberg, D. N.: A variationally derived, depth-integrated approximation to a higher-order glaciological flow model, Journal of Glaciology 57, 2011

Greve, R., Saito, F., and Abe-Ouchi, A.: Initial results of the SeaRISE numerical experiments with the models SICOPOLIS and IcIES for the Greenland ice sheet, Annals of Glaciology 52, 23-30, 2011

Halfar, P.: On the Dynamics of Ice Sheets, Journal of Geophysical Research 86, 11065-11072, 1981

Huybrechts, P.: The Antarctic ice sheet and environmental change: a three-dimensional modelling study, Berichte zur

10 Polarforschung 99, 1992

Huybrechts, P., Payne, T., Abe-Ouchi, A., Calov, R., Fabre, A., Fastook, J. L., Greve, R., Hindmarsh, R. C. A., Hoydal, O., Johannesson, T., MacAyeal, D. R., Marsiat, I., Ritz, C., Verbitsky, M. Y., Waddington, E. D., and Warner, R.: The EISMINT benchmarks for testing ice-sheet models, Annals of Glaciology 23, 1-12, 1996

Lazeroms, W. M. J., Jenkins, A., Gudmunsson, G. H., and van de Wal, R. S. W.: Modelling present-day basal melt rates for

15 Antarctic ice shelves using a parametrization of buoyant meltwater plumes, The Cryosphere 12, 49-70, 2018

Leguy, G. R., Lipscomb, W. H., and Asay-Davis, X. S.: Marine ice sheet experiments with the Community Ice Sheet Model, The Cryosphere 15, 3229-3253, 2021

Levermann, A., Winkelmann, R., Albrecht, T., Goelzer, H., Golledge, N. R., Greve, R., Huybrechts, P., Jordan, J., Leguy, G. R., Martin, D. F., Morlighem, M., Pattyn, F., Pollard, D., Quiquet, A., Rodehacke, C., Seroussi, H., Sutter, J., Zhang, T., Van

20 Breedam, J., Calov, R., DeConto, R. M., Dumas, C., Garbe, J., Gudmunsson, G. H., Hoffman, M. J., Humbert, A., Kleiner, T., Lipscomb, W. H., Meinshausen, M., Ng, E. G., Nowicki, S., Perego, M., Price, S. F., Saito, F., Schlegel, N.-J., Sun, S., and van de Wal, R. S. W.: Projecting Antarctica's contribution to future sea level rise from basal ice shelf melt using linear response functions of 16 ice sheet models (LARMIP-2), Earth System Dynamics 11, 35-76, 2020

Lipscomb, W. H., Price, S. F., Hoffman, M. J., Leguy, G. R., Bennett, A. R., Bradley, S. L., Evans, K. J., Fyke, J. G., Kennedy,

25 J. H., Perego, M., Ranken, D. M., Sacks, W. J., Salinger, A. G., Vargo, L. J., and Worley, P. H.: Description and evaluation of the Community Ice Sheet Model (CISM) v2.1, Geoscientific Model Development 12, 387-424, 2019

Morlighem, M., Rignot, E., Binder, T., Blankenship, D. D., Drews, R., Eagles, G., Eisen, O., Ferraccioli, F., Forsberg, R., Fretwell, P., Goel, V., Greenbaum, J. S., Gudmundsson, H., Guo, J., Helm, V., Hofstede, C., Howat, I., Humbert, A., Jokat, W., Karlsson, N. B., Lee, W. S., Matsuoka, K., Millan, R., Mouginot, J., Paden, J., Pattyn, F., Roberts, J., Rosier, S., Ruppel,

30 A., Seroussi, H., Smith, E. C., Steinhage, D., Sun, B., van den Broeke, M. R., Van Ommen, T. D., van Wessem, M., and Young, D. A.: Deep glacial troughs and stabilizing ridges unveiled beneath the margins of the Antarctic ice sheet, Nature Geoscience 13, 132-138, 2019

Oppenheimer, M., Glavovic, B., Hinkel, J., van de Wal, R. S. W., Magnan, A. K., Abd-Elgawad, A., Cai, R., Cifuentes-Jar, R., DeConto, R. M., Ghosh, T., Hay, J., Isla, F., Marzeion, B., Meyssignac, B., Sebesvari, Z.: Sea Level Rise and Implications 
for Low Lying Islands, Coasts, and Communities, in: IPCC Spe- cial Report on the Ocean and Cryosphere in a Changing Climate, edited by: Pörtner, H.-O., Roberts, D. C., Masson-Delmotte, V., Zhai, P., Tignor, M., Poloczanska, E., Mintenbeck, K., Nicolai, M., Okem, A., Petzold, J., Rama, B., and Weyer, N., 2019

Pattyn, F., Perichon, L., Aschwanden, A., Breuer, B., de Smedt, B., Gagliardini, O., Gudmunsson, G. H., Hindmarsh, R. C. 5 A., Hubbard, A., Johnson, J. V., Kleiner, T., Konovalov, Y., Martin, C., Payne, A. J., Pollard, D., Price, S. F., Rückamp, M., Saito, F., Souček, O., Sugiyama, S., and Zwinger, T.: Benchmark experiments for higher-order and full-Stokes ice sheet models (ISMIP-HOM), The Cryosphere 2, 95-108, 2008

Pattyn, F., Schoof, C., Perichon, L., Hindmarsh, R. C. A., Bueler, E., de Fleurian, B., Durand, G., Gagliardini, O., Gladstone, R. M., Goldberg, D., Gudmunsson, G. H., Huybrechts, P., Lee, V., Nick, F. M., Payne, A. J., Pollard, D., Rybak, O., Saito, F., 10 and Vieli, A.: Results of the Marine Ice Sheet Model Intercomparison Project, MISMIP, The Cryosphere 6, 573-588, 2012 Pattyn, F.: Sea-level response to melting of Antarctic ice shelves on multi-centennial timescales with the fast Elementary Thermomechanical Ice Sheet model (f.ETISh v1.0), The Cryosphere 11, 1851-1878, 2017

Payne, A. J., Nowicki, S., Abe-Ouchi, A., Agosta, C., Alexander, P., Albrecht, T., Asay-Davis, X. S., Aschwanden, A., Barthel, A., Bracegirdle, T. J., Calov, R., Chambers, C., Choi, Y., Cullather, R., Cuzzone, J. K., Dumas, C., Edwards, T. L., Felikson, 15 D., Fettweis, X., Galton-Fenzi, B. K., Goelzer, H., Gladstone, R. M., Golledge, N. R., Gregory, J. M., Greve, R., Hattermann, T., Hoffman, M. J., Humbert, A., Huybrechts, P., Jourdain, N. C., Kleiner, T., Kuipers Munneke, P., Larour, E., Le Clec'h, S., Lee, V., Leguy, G. R., Lipscomb, W. H., Little, C. M., Lowry, D. P., Morlighem, M., Nias, I., Pattyn, F., Pelle, T., Price, S. F., Quiquet, A., Reese, R., Rückamp, M., Schlegel, N.-J., Seroussi, H., Shepherd, A., Simon, E. G., Slater, D. A., Smith, R. S., Straneo, F., Sun, S., Tarasov, L., Trusel, L. D., Van Breedam, J., van de Wal, R. S. W., van den Broeke, M. R., Winkelmann,

20 R., Zhao, C., Zhang, T., and Zwinger, T.: Future Sea Level Change Under Coupled Model Intercomparison Project Phase 5 and Phase 6 Scenarios From the Greenland and Antarctic Ice Sheets, Geophysical Research Letters 48, https://doi. org/10.1029/2020GL091741, 2021

Pollard, D. and DeConto, R. M.: Description of a hybrid ice sheet-shelf model, and application to Antarctica, Geoscientific Model Development 5, 1273-1295, 2012

25 Quiquet, A., Dumas, C., Ritz, C., Peyaud, V., and Roche, D. M.: The GRISLI ice sheet model (version 2.0): calibration and validation for multi-millennial changes of the Antarctic ice sheet, Geoscientific Model Development 11, 5003-5025, 2018

Reerink, T. J., Kliphuis, M. A., and van de Wal, R.: Mapping technique of climate fields between GCM's and ice models, Geoscientific Model Development 3, 13-41, 2010

Reerink, T. J., van de Berg, W. J., and van de Wal, R. S. W.: OBLIMAP 2.0: a fast climate model - ice sheet model coupler

30 including online embeddable mapping routines, Geoscientific Model Development 9, 4111-4132, 2016

Reese, R., Winkelmann, R., and Gudmunsson, G. H.: Grounding-line flux formula applied as a flux condition in numerical simulations fails for buttressed Antarctic ice streams, The Cryosphere 12, 3229-3242, 2018a

Reese, R., Albrecht, T., Mengel, M., Asay-Davis, X. S., and Winkelmann, R.: Antarctic sub-shelf melt rates via PICO, The Cryosphere 12, 1969-1985, 2018b 
https://doi.org/10.5194/gmd-2021-352

Preprint. Discussion started: 4 January 2022

(c) Author(s) 2022. CC BY 4.0 License.

(c) (i)

Robinson, A., Alvarez-Solas, J., Montoya, M., Goelzer, H., Greve, R., and Ritz, C.: Description and validation of the ice-sheet model Yelmo (version 1.0), Geoscientific Model Development 13, 2805-2823, 2020

Robinson, A., Goldberg, D. N., and Lipscomb, W. H.: A comparison of the performance of depth-integrated ice-dynamics solvers, The Cryosphere Discussions, https://doi.org/10.5194/tc-2021-239, 202

5 Schoof, C.: A variational approach to ice stream flow, Journal of Fluid Mechanics 556, 227-251, 2006

Seroussi, H., Nowicki, S., Simon, E. G., Abe-Ouchi, A., Albrecht, T., Brondex, J., Cornford, S. L., Dumas, C., Gillet-Chaulet, F., Goelzer, H., Golledge, N. R., Gregory, J. M., Greve, R., Hoffman, M. J., Humbert, A., Huybrechts, P., Kleiner, T., Larour, E., Leguy, G. R., Lipscomb, W. H., Lowry, D. P., Mengel, M., Morlighem, M., Pattyn, F., Payne, A. J., Pollard, D., Price, S. F., Quiquet, A., Reerink, T. J., Reese, R., Rodehacke, C., Schlegel, N.-J., Shepherd, A., Sun, S., Sutter, J., Van Breedam, J.,

10 van de Wal, R. S. W., Winkelmann, R., and Zhang, T.: initMIP-Antarctica: an ice sheet model initialization experiment of ISMIP6, The Cryosphere 13, 1441-1471, 2019

Seroussi, H., Nowicki, S., Payne, A. J., Goelzer, H., Lipscomb, W. H., Abe-Ouchi, A., Agosta, C., Albrecht, T., Asay-Davis, X. S., Barthel, A., Calov, R., Cullather, R., Dumas, C., Galton-Fenzi, B. K., Gladstone, R. M., Golledge, N. R., Gregory, J. M., Greve, R., Hattermann, T., Hoffman, M. J., Humbert, A., Huybrechts, P., Jourdain, N. C., Kleiner, T., Larour, E., Leguy,

15 G. R., Lowry, D. P., Little, C. M., Morlighem, M., Pattyn, F., Pelle, T., Price, S. F., Quiquet, A., Reese, R., Schlegel, N.-J., Shepherd, A., Simon, E. G., Smith, R. S., Straneo, F., Sun, S., Trusel, L. D., Van Breedam, J., van de Wal, R. S. W., Winkelmann, R., Zhao, C., Zhang, T., and Zwinger, T.: ISMIP6 Antarctica: a multi-model ensemble of the Antarctic ice sheet evolution over the 21 st century, The Cryosphere 14, 3033-3070, 2020

Shapiro, N. M. and Ritzwoller, M. H.: Inferring surface heat flux distributions guided by a global seismic model: particular

20 application to Antarctica, Earth and Planetary Science Letters 223, 213-224, 2004

Singarayer, J. S. and Valdes, P. J.: High-latitude climate sensitivity to ice-sheet forcing over the last 120 kyr, Quaternary Science Reviews 29, 43-55, 2010

Spada, G. and Stocchi, P.: SELEN: A Fortran 90 program for solving the "sea-level equation", Computers \& Geosciences 33 , 538-562, 2007

25 Sun, S., Pattyn, F., Simon, E. G., Albrecht, T., Cornford, S. L., Calov, R., Dumas, C., Gillet-Chaulet, F., Goelzer, H., Golledge, N. R., Greve, R., Hoffman, M. J., Humbert, A., Kazmierczak, E., Kleiner, T., Leguy, G. R., Lipscomb, W. H., Martin, D., Morlighem, M., Nowicki, S., Pollard, D., Price, S. F., Quiquet, A., Seroussi, H., Schlemm, T., Sutter, J., van de Wal, R. S. W., Winkelmann, R., and Zhang, T.: Antarctic ice sheet response to sudden and sustained ice-shelf collapse (ABUMIP), Journal of Glaciology 66, 891-904, 2020

30 Tsai, V. C., Stewart, A. L., and Thompson, A. F.: Marine ice-sheet profiles and stability under Coulomb basal conditions, Journal of Glaciology 61, 205-215, 2015

van de Wal, R. S. W., Zhang, X., Minobe, S., Jevrejeva, S., Riva, R. E. M., Little, C., Richter, K., and Palmer, M. D.: Uncertainties in Long-Term Twenty-First Century Process-Based Coastal Sea-Level Projections, Surveys in Geophysics 40, 1655-1671, 2019 
https://doi.org/10.5194/gmd-2021-352

Preprint. Discussion started: 4 January 2022

(c) Author(s) 2022. CC BY 4.0 License.

(c) (i)

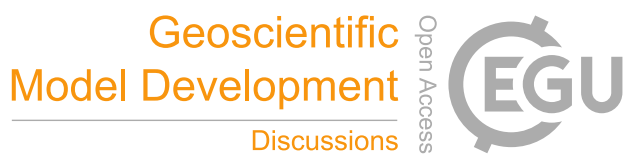

van Wessem, J. M., Reijmer, C. H., Morlighem, M., Mouginot, J., Rignot, E., Medley, B., Joughin, I., Wouters, B., Depoorter, M. A., Bamber, J. L., Lenaerts, J. T. M., van de Berg, W. J., van den Broeke, M. R., and van Meijgaard, E.: Improved representation of East Antarctic surface mass balance in a regional atmospheric climate model, Journal of Glaciology 60, 761770,2014 